\title{
Combined effect of the Arctic Oscillation and the Western Pacific pattern on East Asia winter temperature
}

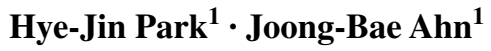

Received: 24 December 2014 / Accepted: 11 July 2015 / Published online: 23 July 2015

(C) The Author(s) 2015. This article is published with open access at Springerlink.com

\begin{abstract}
The combined effect of the Arctic Oscillation (AO) and Western Pacific (WP) teleconnection pattern on the temperature variation during the winter in the northern hemisphere and East Asia over the last 56 years (1958/1959-2013/2014) was investigated using NCEP/ NCAR reanalysis data. The study results revealed that the effect of the AO on winter temperature in East Asia could be changed depending on the phase of the WP pattern in the North Pacific. The negative relationship between the temperature of East Asia $\left(25-45^{\circ} \mathrm{N}, 110-145^{\circ} \mathrm{E}\right)$ and the $\mathrm{AO}$ increased when the AO and WP were in-phase with each other. Hence, when winter negative (positive) AO was accompanied by negative (positive) WP, negative (positive) temperature anomalies were dominant across the entire East Asia region. Conversely, when the AO and WP were out-of-phase, the winter temperature anomaly in East Asia did not show distinct changes. Furthermore, from the perspective of stationary planetary waves, the zonal wavenumber- 2 patterns of sea level pressure and geopotential height at $500 \mathrm{hPa}$ related to the East Asian winter monsoon (EAWM) circulation strengthened when the AO and WP were in-phase but were not significant for the out-of-phase condition. An index considering the effect of both $\mathrm{AO}$ and WP on East Asia winter temperature was proposed. The correlation between the index and the East Asia winter temperature was statistically significant at the $99 \%$ confidence level. The index was correlated with synoptic characteristics of the EAWM, including the Siberian High, East Asian trough, East Asian jet stream and surface air temperature.
\end{abstract}

Joong-Bae Ahn

jbahn@pusan.ac.kr

1 Division of Earth Environmental System, Pusan National University, Pusan 609-735, Republic of Korea
Keywords Arctic Oscillation (AO) $\cdot$ Western Pacific (WP) pattern · East Asia winter temperature · East Asian winter monsoon

\section{Introduction}

The East Asian winter monsoon (EAWM) is one of the most active climate systems in the northern hemisphere in the boreal winter, and is caused by the thermal contrast between the Eurasian continent and the Indian and Pacific Oceans (Wu and Wang 2002; Wang et al. 2010). The EAWM is characterized by the northwesterly wind over the east coast of Eurasia caused by the pressure gradient between the Siberian High in the Eurasian continent and the Aleutian Low in the North Pacific, the East Asian trough (EAT) in mid-latitude and the polar jet stream near the south of Japan in the upper troposphere (Jhun and Lee 2004; Chen et al. 2013). Variations of these characteristics affect temperature and precipitation during the boreal winter in East Asia.

The Arctic Oscillation (AO), as the first leading mode of extratropical climate variation over the north hemisphere during the boreal winter, is a large-scale barotropic seesaw pattern, in which the sea level pressure (SLP) anomaly over the Arctic basin has an opposite sign to the anomalies over two oceans (the North Atlantic and North Pacific) in the mid-latitude of the north hemisphere (Thompson and Wallace 1998). The AO strongly affects the winter climates of the Eurasian continent and Euro-Atlantic Ocean (Thompson and Wallace 1998, 2000, 2001) and the winter climate over the North Pacific on the decadal timescale (Sun and Wang 2006).

Studies on the relationship between the variability of the AO and EAWM have been recently conducted (Gong et al. 
2001, Jhun and Lee 2004; Jeong and Ho 2005; Park et al. 2011; Li et al. 2014). At the interannual time scale, Gong et al. (2001) stated that the AO affects the intensity of the Siberian High and consequently the winter temperature changes in East Asia. In the negative AO phase, Jeong and Ho (2005) showed that the cold surge frequency in East Asia is higher than that in normal years and Park et al. (2011) revealed that the blocking type circulation pattern related to the cold surge over East Asia occurs more frequently than the wave train type pattern. Li et al. (2014) showed that the relationship between the variability of the AO and EAWM strengthened after the 1980s through upstream extension of the East Asian jet stream (EAJS) in connection with the reduction of autumn Arctic sea ice cover. In addition, several previous studies presented mechanisms to explain occurrence of negative AO that could influence on EAWM (Wang and Chen 2010; Cohen et al. 2010). Wang and Chen (2010) and Cohen et al. (2010) showed that the downward stationary planetary wave propagation gives rise to the negative $\mathrm{AO}$ pattern at the surface and this downward propagation is attributed to the upward propagation of stationary planetary waves from the troposphere to the stratosphere.

At the interseasonal and interannual time scales, the North Atlantic part of the AO is spatially similar to the first leading mode of atmospheric circulation anomalies over the Atlantic-European sector (e.g., North Atlantic Oscillation, NAO), and the correlation coefficient between their time series is also high (Deser 2000; Thompson and Wallace 1998; Greatbatch 2000). On the other hand, the Pacific North America (PNA) and Western Pacific (WP) patterns, which are the first two leading modes of atmospheric circulation anomalies at mid-latitudes over the Pacific sector (Wallace and Gutzler 1981; Barnston and Livezey 1987; Minobe and Mantua 1999; Holton et al. 2002), have a low temporal correlation with the AO, unlike the NAO (Deser 2000; http://www.esrl.noaa.gov/psd/data/correlation/table. html).

East Asia is located on the western border of the North Pacific mid-latitudes, and is therefore affected not only by the AO but also by the major atmospheric circulation patterns of the North Pacific. Recent studies have been conducted on the effect of the $\mathrm{AO}$ and the atmosphere and ocean circulation patterns of the North Pacific on the EAWM. Kim and Ahn (2012) and He and Wang (2013a) revealed that the autumn AO and sea surface temperature of the North Pacific affect the winter temperatures in East Asia via stationary Rossby waves. Furthermore, Chen et al. (2013) examined the combined effects of the winter AO and El Niño-Southern Oscillation (ENSO) on the EAWM. They showed that when a negative AO accompanies El Niño or a positive AO accompanies La Niña, the AO strongly affects the temperature and precipitation anomalies in northern China, while ENSO affects southern China.
ENSO is an interannual phenomenon caused by the unstable interaction between the atmosphere and ocean in the tropical Pacific (Rasmusson and Wallace 1983; Chen et al. 2013). The effects of ENSO on the EAWM have been studied (Zhang et al. 1996; Wang et al. 2000; Sakai and Kawamura 2009). However, some studies stated that the effects of ENSO on the EAWM can be changed depending on the North Pacific long-term atmosphere and ocean circulation pattern, such as the Pacific Decadal Oscillation (Wang et al. 2008; He and Wang 2013b; Kim et al. 2014).

The PNA and WP most often affect the intensity and position of the Aleutian Low. A pattern of PNA has the same sign of geopotential anomaly in the central North Pacific and eastern North America and the opposite geopotential anomaly sign in western North America (Wallace and Gutzler 1981; Konrad 1998), affecting the intensity of the Aleutian Low (Chen and Zhai 2011; Xiao et al. 2014). Meanwhile, the WP is a meridional dipole pattern of atmospheric circulation anomalies at the middle/high latitudes of the North Pacific (Wallace and Gutzler 1981), related to the meridional shift of the Aleutian Low (Di Lorenzo et al. 2010). According to the temporal correlation coefficients between either the PNA or the WP and the winter temperature at $2 \mathrm{~m}$ in the East Asian region $\left(25^{\circ}-45^{\circ} \mathrm{N}\right.$, $110^{\circ}-145^{\circ} \mathrm{E}$; Table 1), the winter temperature in East Asia has a higher and statistically more significant correlation with the WP than with the PNA. In addition, previous studies showed that pressure variations in the southwest part of the Aleutian Low related to the variation of the WP are more significantly related to the variation of the EAWM than with the variation in the center of the Aleutian Low (Wu et al. 2006; Wang and Chen 2014). The present study investigates the effect of different AO and WP phases on the East Asia winter temperature.

The datasets and methods utilized in this study are introduced in Sect. 2. In Sect. 3, the effect of the winter $\mathrm{AO}$ and $\mathrm{WP}$ on the winter temperature over the northern

Table 1 Temporal correlation coefficients between temperature at $2 \mathrm{~m}$ over East Asia $\left(25^{\circ}-45^{\circ} \mathrm{N}, 110^{\circ}-145^{\circ} \mathrm{E}\right)$ and different indices during the boreal winter 1958/1959-2013/2014

\begin{tabular}{llll}
\hline & AO & PNA & WP \\
\hline DEC & $0.28^{*}$ & -0.06 & $0.37^{* *}$ \\
JAN & $0.48^{* *}$ & $-0.27^{*}$ & $0.56^{* *}$ \\
FEB & $0.38^{* *}$ & $-0.39^{* *}$ & $0.42^{* *}$ \\
DJF monthly & $0.38^{* *}$ & -0.24 & $0.45^{* *}$ \\
DJF mean & $0.42^{* *}$ & -0.11 & $0.65^{* *}$ \\
\hline
\end{tabular}

The values with one and two asterisks exceed the 95 and $99 \%$ confidence levels according to the two-tailed student's $t$ test, respectively. $\mathrm{SH}$, Siberian High; SL, Aleutian Low; $\mathrm{SH}-\mathrm{AL}$, zonal pressure gradient between SH and AL; EAT, East Asian trough; TAI, trough axis index; EAJS, East Asian jet stream 
hemisphere are examined, and the temperature anomaly patterns are compared when the AO and WP have the same or different phases. Next, the resulting changes in the atmospheric circulation are investigated. Finally, the study results are summarized and discussed in Sect. 4.

\section{Data and methodology}

The datasets of the atmospheric variables used in this study are the monthly means from the reanalysis data of the National Centers for Environmental Prediction (NCEP)/ National Center for Atmospheric Research (NCAR; Kalnay et al. 1996). The variables used are air temperature at $2 \mathrm{~m}$ (T2m), SLP, geopotential height at $500 \mathrm{hPa}$ (HGT500), and zonal wind at $300 \mathrm{hPa}$ (U300). The analysis period is the boreal winters (December, and January and February of the following year) from $1958 / 1959$ to $2013 / 2014$, and the horizontal resolution of the data is $2.5^{\circ} \times 2.5^{\circ}$ in longitude and latitude.

The monthly AO and WP teleconnection indices, supplied by the National Oceanic and Atmospheric Administration Climate Prediction Center (NOAA CPC), were utilized. NOAA CPC defines the AO pattern as the first leading empirical orthogonal function mode of the geopotential height anomaly at $1000 \mathrm{hPa}$ at north of $20^{\circ} \mathrm{N}$. The positive AO pattern shows a negative geopotential height anomaly centered in the Arctic and positive geopotential height anomalies centered in the North Pacific and North Atlantic of mid-latitude. The monthly AO index is calculated by projecting the geopotential height at $1000 \mathrm{hPa}$ onto the positive AO pattern (http://www.esrl.noaa.gov/ $\mathrm{psd} /$ data/correlation/ao.data). The positive WP pattern, also produced by NOAA CPC, has a negative anomaly of geopotential height centered at the Bering Sea and a positive anomaly of geopotential height situated at the center of the North Pacific (http://www.esrl.noaa.gov/psd/data/ correlation/wp.data). The WP index of NOAA CPC utilized in this study has a sign opposite to that of the index defined by Wallace and Gutzler (1981). The East Asia surface temperature index (T2m_EA) is defined as the areaaveraged temperature at $2 \mathrm{~m}$ in the region of $25^{\circ} \mathrm{N}-45^{\circ} \mathrm{N}$, $110^{\circ} \mathrm{E}-145^{\circ} \mathrm{E}$ in this study. This region includes eastern China, the Korean Peninsula, and Japan.

In this study, the monthly data, instead of the seasonal mean, of all the reanalysis data and climate indices are used for analysis to obtain a sufficient number of samples for each group when the months are categorized by the AO and WP phases. The anomaly of the variable is calculated by eliminating the monthly climatology from each monthly mean. In addition, each of the indices is normalized by dividing the monthly anomaly by the standard deviation of each month.
In order to categorize the months by the $\mathrm{AO}$ and WP phases, first, monthly AO and WP indices of each month are defined as positive (negative) AO and WP months when monthly AO and WP indices are larger (smaller) than the 0.44 $(-0.44)$ standard deviation, respectively. A standard deviation of \pm 0.44 is the threshold of the standard distribution where samples (months) are divided into three (33\% each) categories (positive, normal and negative months). The positive (negative) months in this study denote months in which each index is above (below) normal. A total of 168 months (56 years $\times 3$ months) are categorized into four different groups depending on the AO and WP phase combination, as shown in Table 2. A composite analysis is carried out to examine the temperature anomaly and resulting atmospheric circulation anomalies for each group, and the statistical significance is evaluated using the two-tailed student's $t$ test.

\section{Results}

\subsection{Individual influences of the AO and WP}

Figure 1 shows the time series of monthly T2m_EA and atmospheric circulation indices of the northern hemisphere and North Pacific (AO, PNA and WP) during the boreal winter months of December 1958 to February 2014 (total 168 months). The simultaneous temporal correlation coefficients between all three indices and T2m_EA are statistically significant at the $99 \%$ confidence level. The AO and WP are positively correlated with T2m_EA, but the PNA is negatively correlated. The correlation coefficient between T2m_EA and WP is 0.45 , which is higher than that between T2m_EA and AO (0.38). This shows that the WP has a higher correlation than the AO with the East Asia winter temperature variation. The correlation coefficients between T2m_EA and the indices for each month are summarized in Table 1 . The AO index and T2m_EA have a statistically significant positive correlation with the $95 \%$ confidence level for all winter months. The PNA has negative simultaneous correlations with the January and February T2m_EA with $95 \%$ confidence level, but it has no statistical relation with the December T2m_EA, as the correlation coefficient is -0.06 . On the other hand, the WP has statistically positive significant temporal correlations with T2m_EA for all winter months with the $99 \%$ confidence level. This implies that the WP is strongly related to T2m_EA, although the AO still affects the temperature over the region.

A composite analysis is performed to examine the spatial patterns of the variables in terms of the phases of the $\mathrm{AO}$ and WP. Figure 2 is the composites of SLP (Fig. 2a, b, respectively) and $\mathrm{T} 2 \mathrm{~m}$ (Fig. 2c, d, respectively) anomalies during negative and positive AO months, respectively. Of 
a total of 168 months, 53 are positive AO months and 54 are negative $\mathrm{AO}$ months based on the classification method in Sect. 2. The SLP and T2m anomalies patterns of negative $\mathrm{AO}$ in the northern hemisphere is similar to those of positive AO except with opposite signs. When the AO is negative (Fig. 2a), a positive SLP anomaly is positioned at high latitude centered around the North Pole and the centers of the two negative SLP anomalies are positioned at the mid-latitude of the eastern North Atlantic and south of the Aleutian islands of the North Pacific, which is the typical pattern of the negative AO (Thompson and Wallace 1998). This implies a southward shift of the Icelandic Low and the weakening of the Azores High in the North Atlantic. The positive SLP anomalies centered at the North Pole stretch out in the northern Siberia and northern North America, signifying the northward expansion of the Siberian and Canadian Highs, respectively. An anomalous negative T2m appears from northern Europe, across Siberia and the eastern United States, and an anomalous positive $\mathrm{T} 2 \mathrm{~m}$ appears to be statistically significant in Greenland, Baffin Bay, and southwestern Europe (Fig. 2c). When the $\mathrm{AO}$ is positive, the overall pattern of SLP and T2m anomalies is opposite to that of negative AO months (Fig. 2b, d). However, in the northern Pacific, SLP anomalies of the positive $\mathrm{AO}$ expand more to the west than that of the negative $\mathrm{AO}$, and show statistically significant temperature anomalies in the East Asian regions.

Figure 3 shows the HGT500 and T2m anomalies in terms of the WP phase. The numbers of month for the negative and positive WP are 54 and 58 of a total of 168 months, respectively. The temperature and atmospheric circulation patterns related to the WP phase are statistically significant within the eastern Eurasian continent and North Pacific regions. In the case of the negative WP, the geopotential height in $500 \mathrm{hPa}$ has a meridional dipole structure, in which a positive anomaly is positioned around eastern Siberia and the Kamchatka Peninsula, and a negative anomaly from south of $45^{\circ} \mathrm{N}$ in northern India to the central North Pacific (Fig. 3a). The distribution of T2m anomalies shows positive anomalies centered around the Okhotsk Sea, and negative anomalies from around China to the Korean Peninsula and the southern seas of Japan in the south of the mid-latitude (Fig. 3c). The temperature and middle-level pressure anomaly patterns of a positive WP are similar, but have opposite signs, to those of a negative WP (Fig. 3b, d).

According to the composite analysis, the winter temperature anomalies related to the AO and WP are not statistically significant in the whole East Asian regions, including eastern China, the Korean Peninsula, and Japan. However, the AO has a significant relationship with temperatures of the Manchurian region in the north part of East Asia, and the WP is related to the temperatures in southern China and the East China Sea located in the south part of East Asia. 
Fig. 1 Time series of monthly temperature anomalies at $2 \mathrm{~m}$ averaged in the East Asia region $\left(25^{\circ}-45^{\circ} \mathrm{N}, 110^{\circ}-145^{\circ} \mathrm{E}\right)$

(T2mEA, blue dot) and monthly index (bar) of a AO, b PNA and c WP during winter (December, Janauary and February) of 1958/1959-2013/2014. The color bars denote the deferent winter month (green: December, yellow-green: January of the next year and yellow: February of the next year). The values in the top right-hand corner denote the correlation coefficients between $\mathrm{T} 2 \mathrm{mEA}$ and the indices (a) $\mathrm{AO}$

$\mathrm{CORR}=0.38$

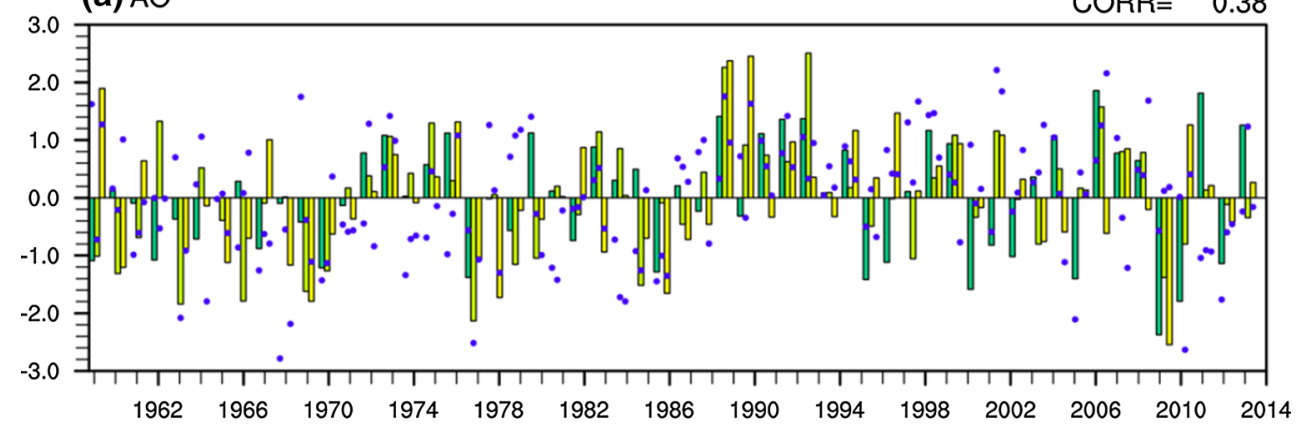

(b) PNA

$\mathrm{CORR}=-0.24$

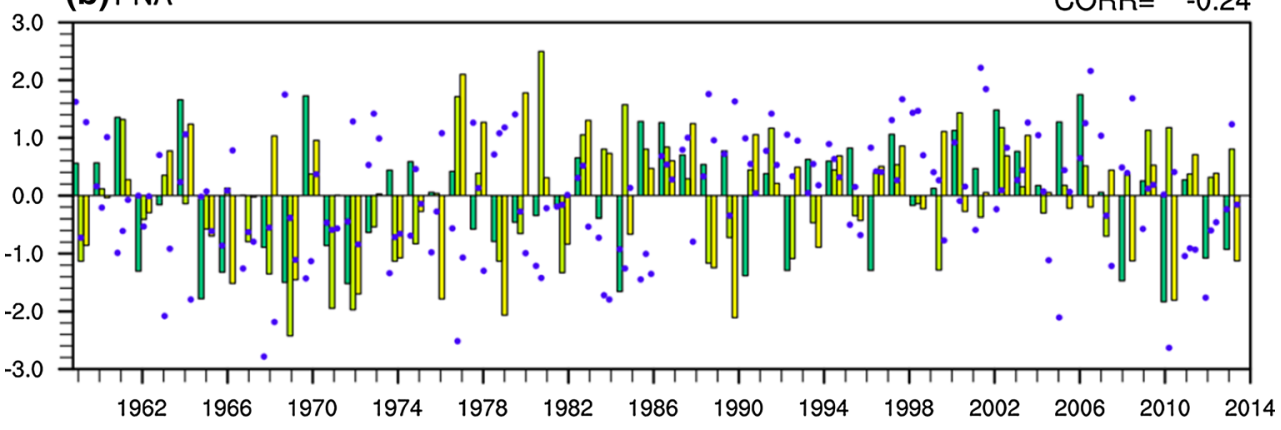

(c) WP

$\mathrm{CORR}=0.45$

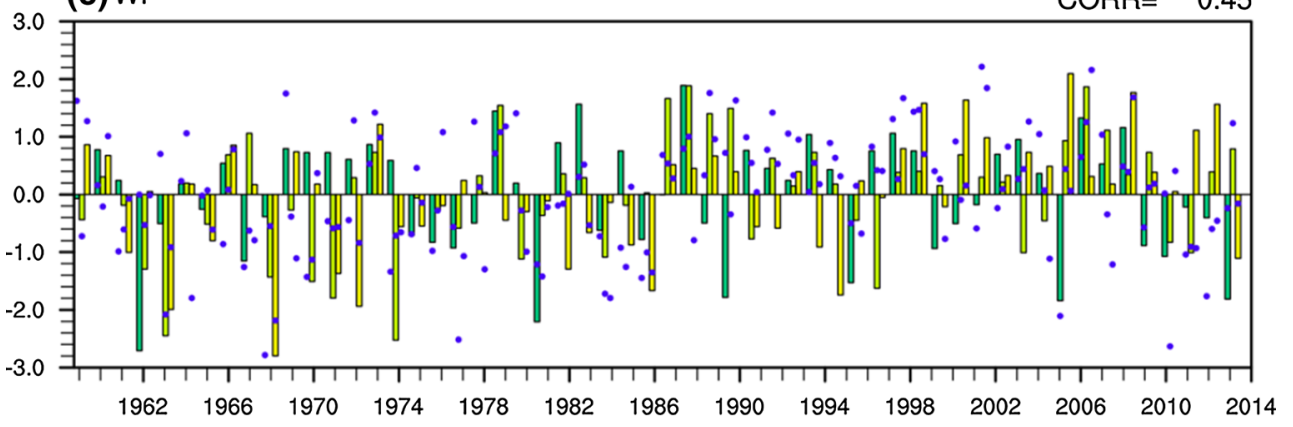

\subsection{Combined effect of the AO and WP on East Asia winter temperature}

In order to see the combined effect of the AO and WP depending on their different phases, each month has been categorized into four groups (Table 2), based on the classification in Sect. 2. The number of cases for in-phase groups of the AO and WP are more than those of their out-of-phase groups. The composite fields of T2m anomalies with different AO and WP phase combinations are illustrated in Fig. 4. Figure $4 \mathrm{a}$ (negative WP and negative AO) and Fig. 4d (positive $\mathrm{WP}$ and positive $\mathrm{AO}$ ) are the cases for in-phase $\mathrm{AO}$ and WP, and Fig. 4b (positive WP and negative AO) and Fig. 4c (negative WP and positive $\mathrm{AO}$ ) are for out-of-phase AO and WP. Figure 4a, d, and b, c, show similar distributions but opposite signs, respectively. It is notable that the East Asia region shows a large difference when the AO and WP are in-phase and out-of-phase. That is when both the $\mathrm{AO}$ and WP have negative (positive) phases, statistically significant negative (positive) $\mathrm{T} 2 \mathrm{~m}$ anomalies appear not only in northern Eurasia, but also in Northeastern China, the Korean Peninsula, Japan, and the eastern China Sea located south of $45^{\circ} \mathrm{N}$, and positive (negative) T2m anomalies appear in eastern Siberia (Fig. 4a). Conversely, when a negative (positive) AO is accompanied by a positive (negative) WP, T2m anomalies are significantly negative (positive) only in northern Eurasia but are not significant in East Asian regions (Fig. 4b). This shows that, depending on the WP phase, the effect of the AO on the EAWM can be different.

On the other hand, $\mathrm{T} 2 \mathrm{~m}$ anomalies in regions around the North Atlantic Ocean, independent from the phase of the WP, show patterns in accordance with the phase of the $\mathrm{AO}$ (Figs. 2c, d, and 4). When the AO has a negative (positive) phase, positive (negative) $\mathrm{T} 2 \mathrm{~m}$ anomalies are seen in Greenland and northeastern Canada, and negative (positive) $\mathrm{T} 2 \mathrm{~m}$ anomalies are distributed in the southeastern United States and Europe, similar to Fig. 2c, d. The WP does not 
(a) Negative AO (SLP)

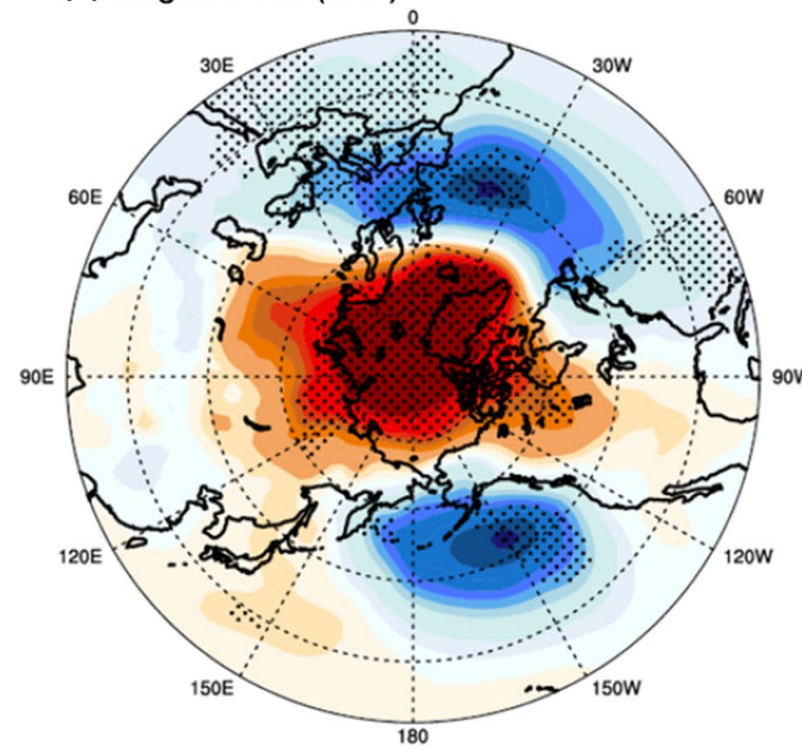

(c) Negative $A O(T 2 M)$

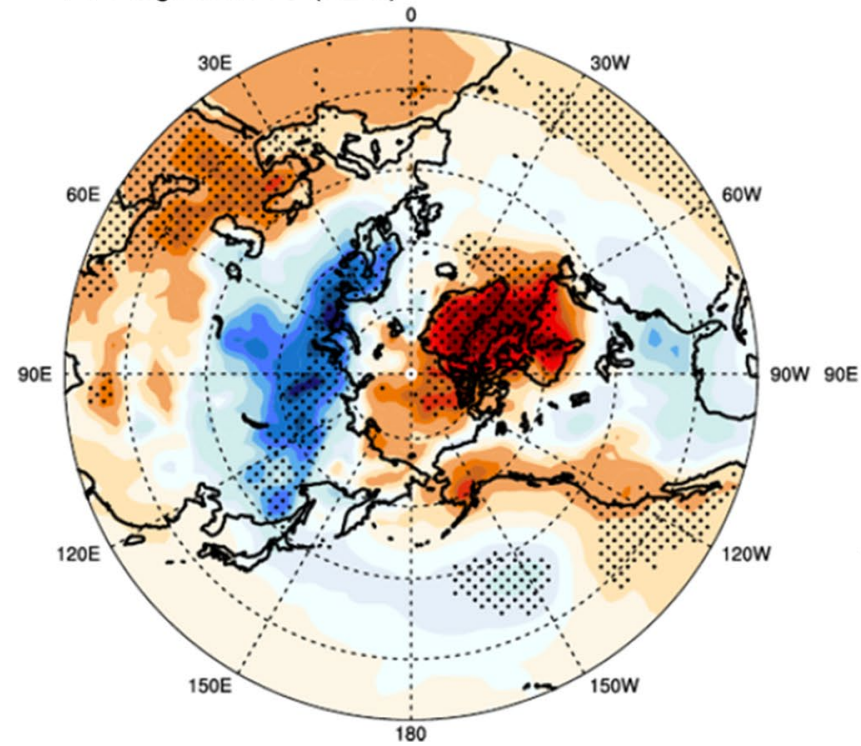

Fig. 2 Composite map of monthly a, $\mathbf{b}$ sea level pressure anomalies and $\mathbf{c}$, $\mathbf{d}$ temperature anomalies at $2 \mathrm{~m}$ in the northern hemisphere during the boreal winter (December, January and February) for the

affect the AO-related winter temperature patterns of the surrounding areas of the North Atlantic.

\subsection{EAWM circulation related to the AO and WP}

The EAWM greatly affects winter temperatures in East Asia. The AO and WP induce changes in EAWM-related atmospheric circulations in East Asia, ultimately affecting the winter temperatures. Therefore, in order to understand the spatial characteristics depending on the different phases (b) Positive AO (SLP)

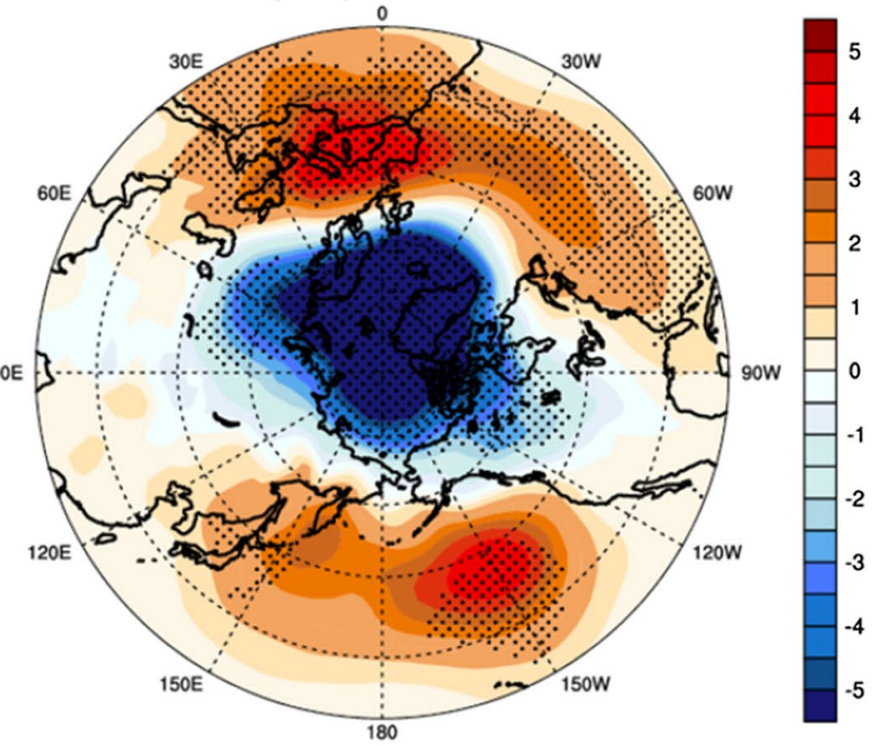

(d) Positive AO (T2M)

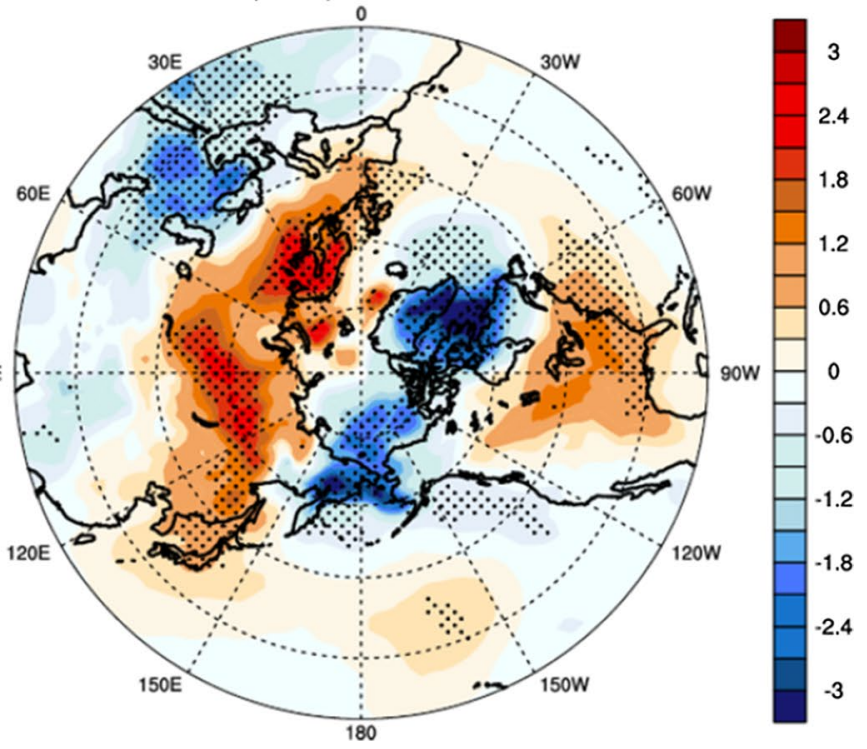

case of $(\mathbf{a}, \mathbf{c})$ negative and $(\mathbf{b}, \mathbf{d})$ positive AO, respectively. Areas with black dots denote $95 \%$ confidence level according to the two-tailed student's $t$ test

of the AO and WP, composites of monthly SLP, HGT500 and U300 of each group were examined. These atmospheric variables well represent the characteristics of the EAWM.

Figure 5 is the composite distribution of monthly SLP (Fig. 5a, b), HGT 500 (Fig. 5c, d), and U300 (Fig. 5e, f) when the AO and WP are in-phase. The atmospheric circulation pattern when the AO and WP are in-phase is generally similar to the atmospheric circulation pattern of a typical AO. When negatively (positively) in-phase, a positive 
(a) Negative WP (HGT500)

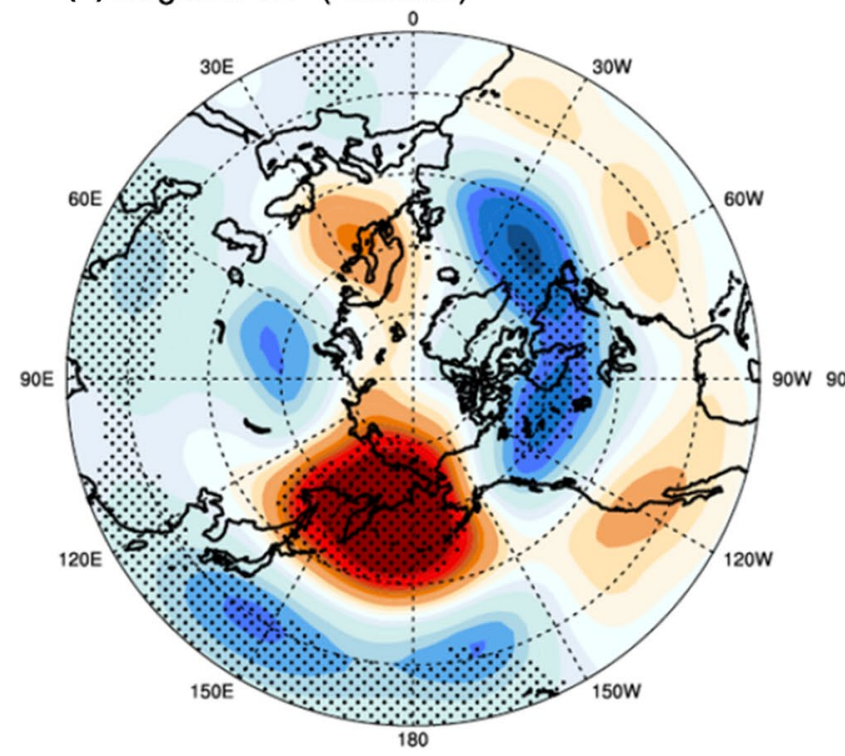

(b) Positive WP (HGT500)

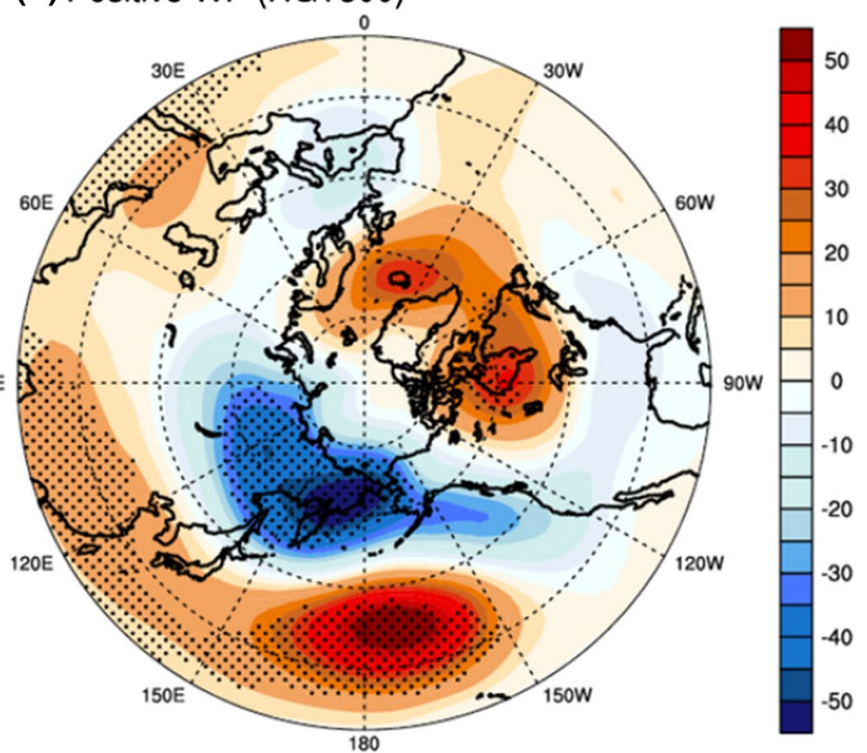

(c) Negative WP (T2M)

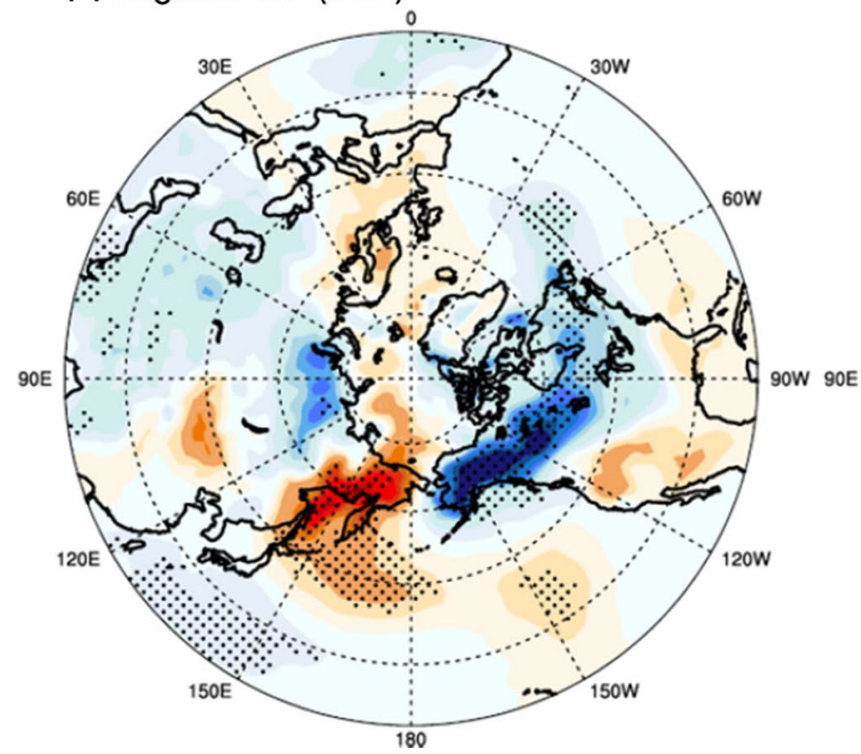

Fig. 3 Composite map of monthly a, b geopotential height anomalies at $500 \mathrm{hPa}$ and $\mathbf{c}, \mathbf{d}$ temperature anomalies at $2 \mathrm{~m}$ in the northern hemisphere during the boreal winter (December, January and Febru-

(negative) SLP anomaly is centered at the North Pole and the centers of the negative (positive) SLP anomalies are located in the North Pacific and North Atlantic. The differences between the in-phased AO and WP patterns and a typical AO are that the atmospheric circulation in the North Pacific is strengthened and expanded toward the west compared to the typical AO pattern. That is, when negatively in-phase, the Aleutian Low expands southwestward in the North Pacific, strengthening the zonal pressure gradient around the Korean Peninsula and Japan, causing cold air to

\section{(d) Positive WP (T2M)}

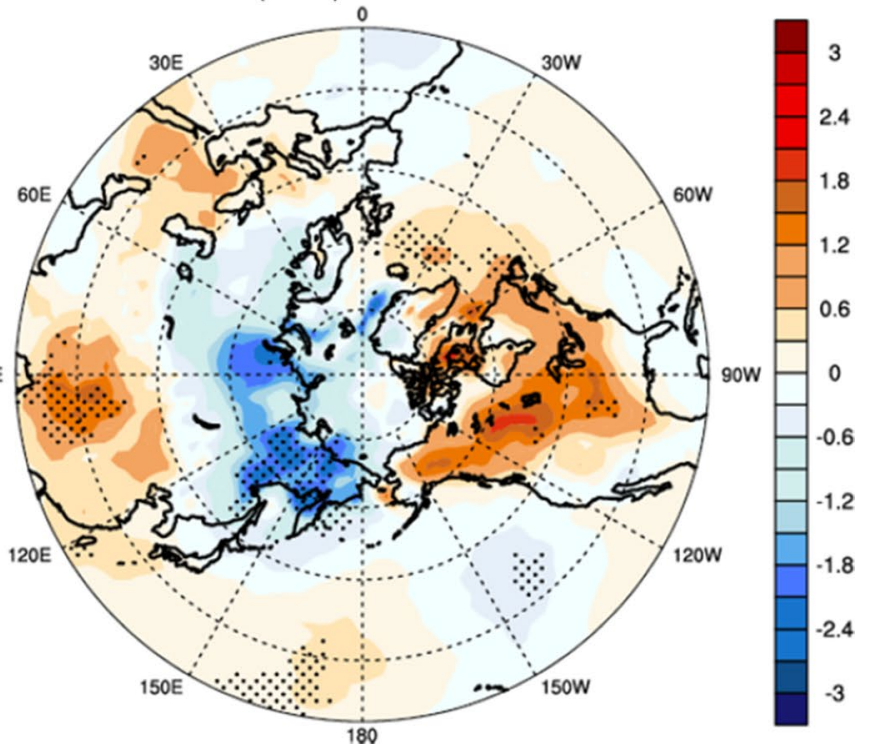

ary) for the case of (a, c) negative and (b, d) positive WP, respectively. Areas with black dots denote $95 \%$ confidence level according to the two-tailed student's $t$ test

flow into East Asia via a northwesterly wind. Conversely, when positively in-phase, the pressure gradient between the Aleutian Low and Siberian High is weakened, and due to the weakening of northwesterly winds, the inflow of cold air decreases compared to that during normal months.

When the AO and WP are in-phase, the circulation structure in the middle level of the troposphere is similar to that in the lower levels, showing a barotropic structure (Fig. 5a, c, and b, d). Climatologically, the cold air from the high latitude flows southeastward towards East Asia, along 
(a) Negative WP/Negative AO

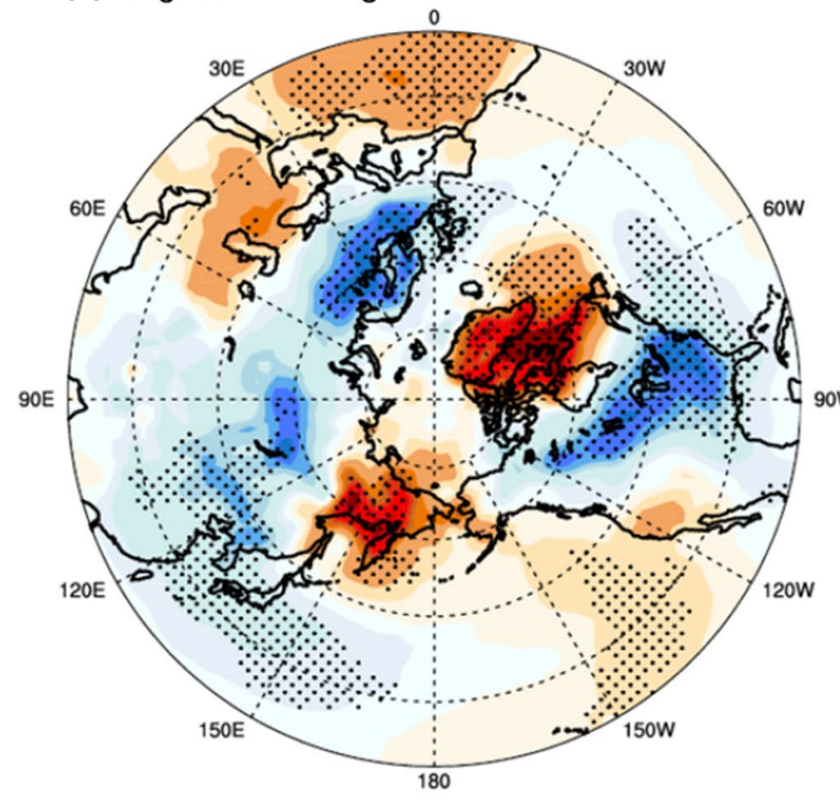

(c) Negative WP/Positive $A O$

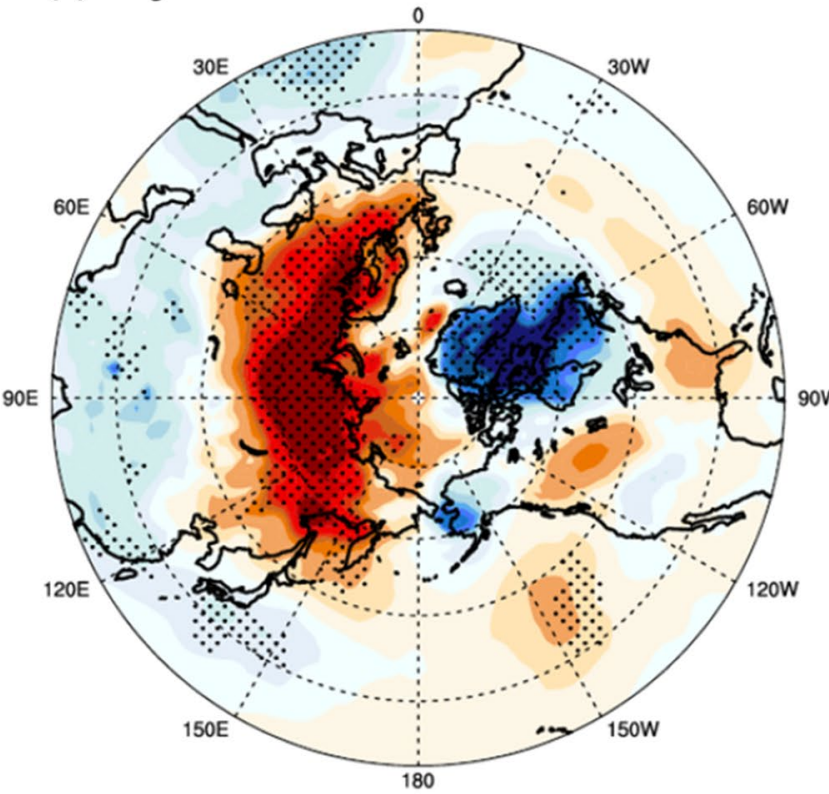

(b) Positive WP/Negative AO

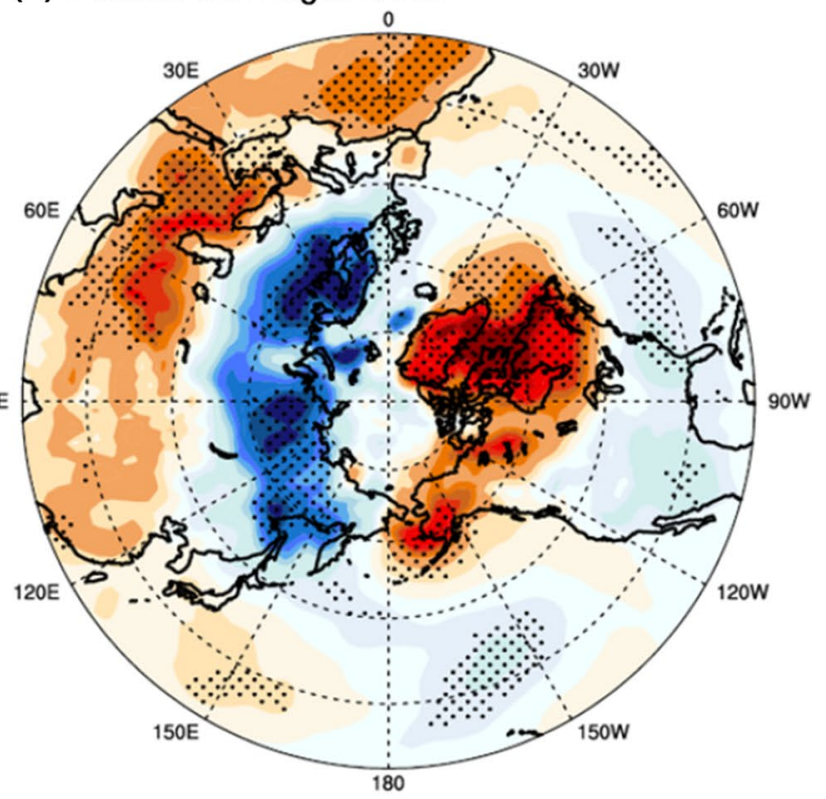

(d) Positive WP/Positive AO

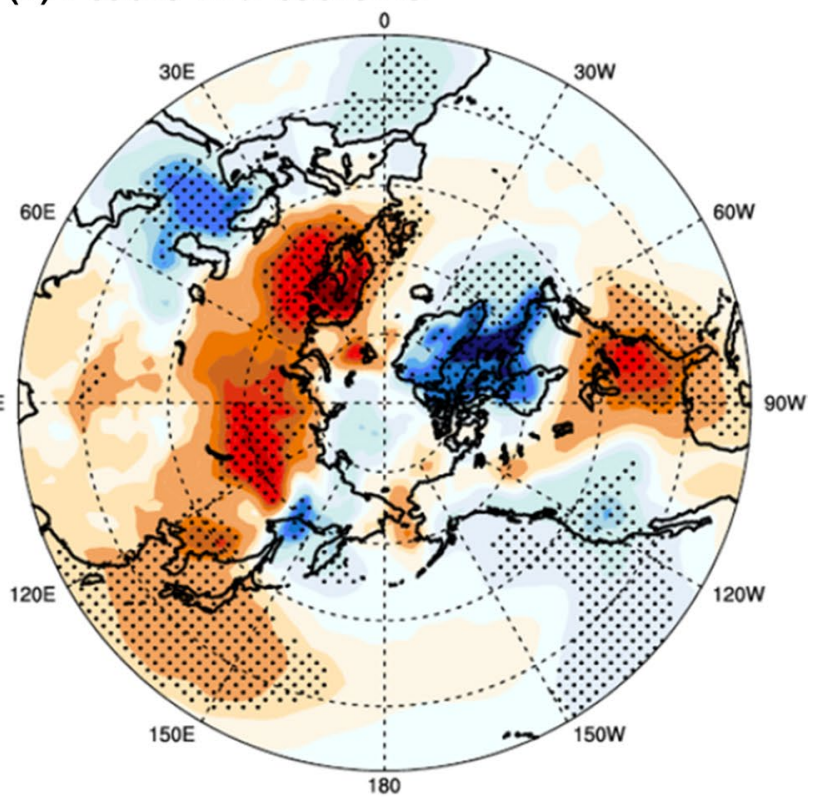

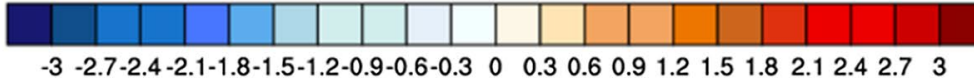

Fig. 4 Composite map of monthly temperature anomalies at $2 \mathrm{~m}$ in the northern hemisphere during the boreal winter (December, January and February) for the case of, a negative WP and negative AO, $\mathbf{b}$ positive WP and negative AO, c negative WP and positive AO, and d positive WP and positive AO. Areas with black dots denote $95 \%$ confidence level according to the two-tailed student's $t$ test the west of the EAT axis from Okhotsk Sea to the Korean Peninsula and Japan (Wang et al. 2009). When the AO and WP are negatively in-phase, anomalous anticyclonic circulation is centered on eastern Siberia and Greenland, and symmetrical anomalous cyclonic circulation is positioned at mid-latitude in the North Pacific and North Atlantic. Anomalous cyclonic circulation in the western North Pacific expands further to the west compared to the case of a typical AO. The EAT becomes deeper, and the cold air in middle level of the troposphere flows in deeply from high 


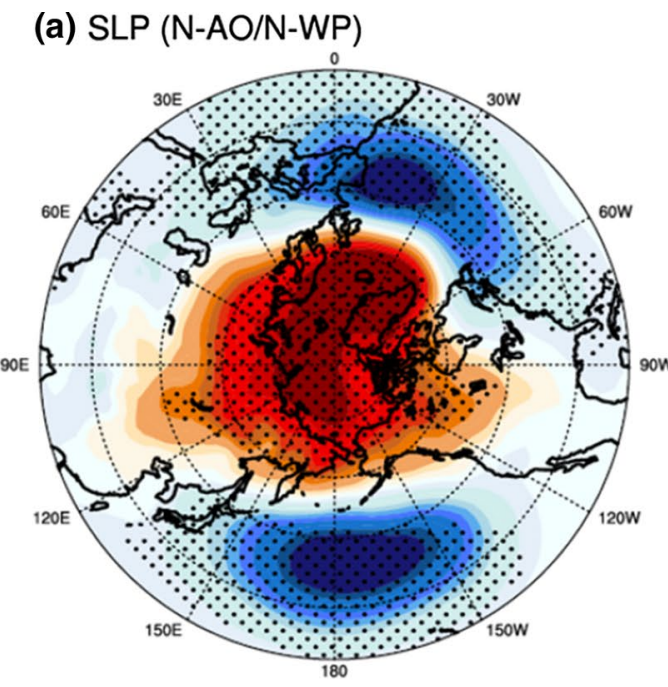

(c) HGT500 (N-AO/N-WP)

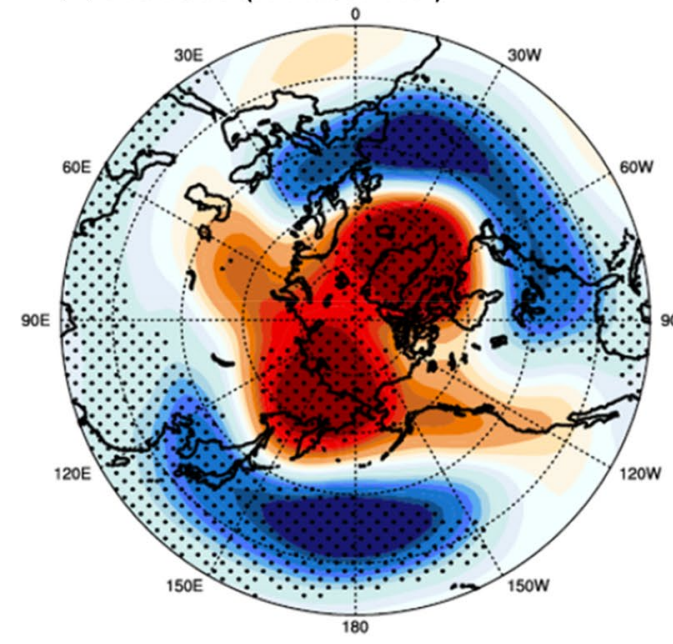

(e) U300 (N-AO/N-WP)

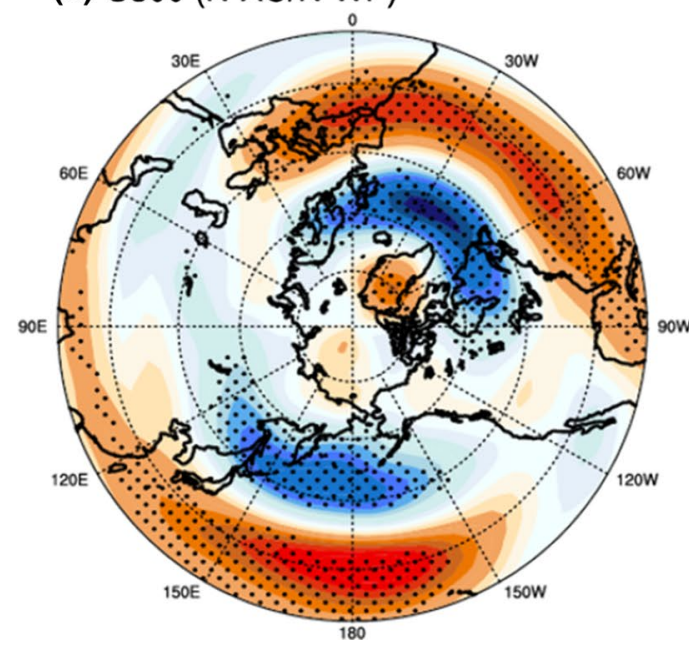

Fig. 5 Composite maps of a sea level pressure anomalies, $\mathbf{b}$ geopotential height anomalies at $500 \mathrm{hPa}$ and $\mathbf{c}$ zonal wind anomalies at $300 \mathrm{hPa}$ for the negative in-phase cases of the AO and WP. The (b), (d) and (f)
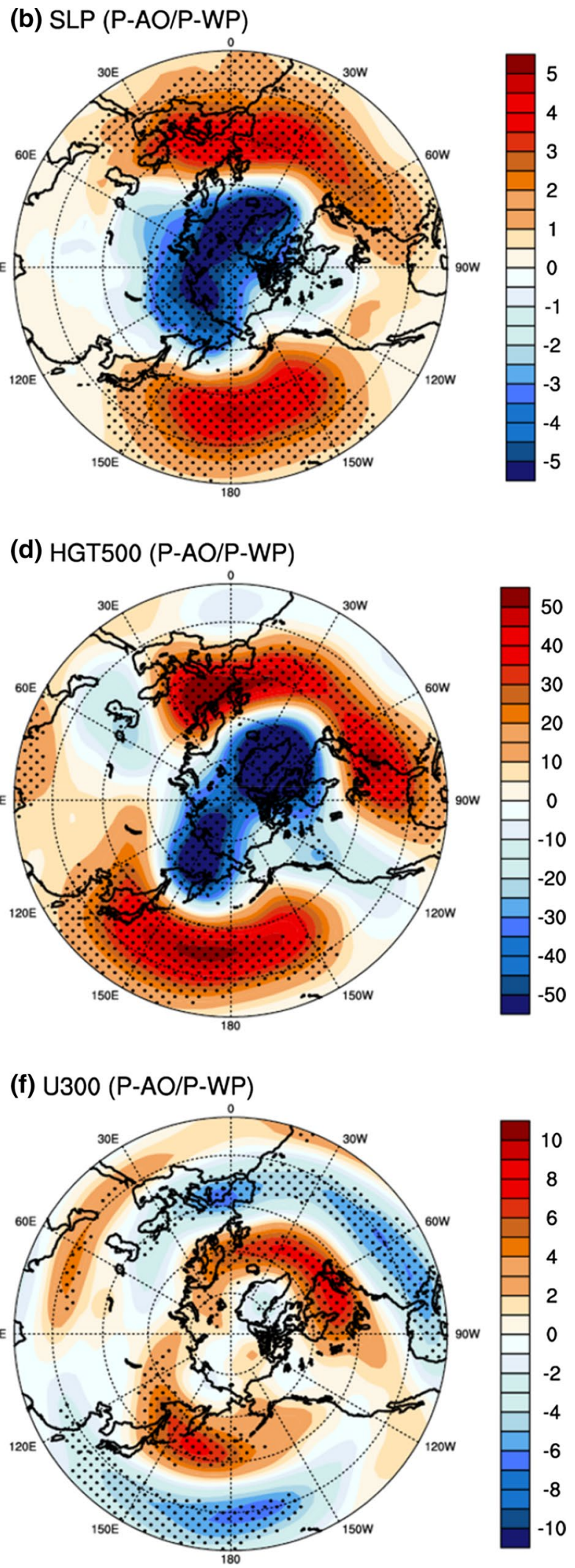

are the same as (a), (c) and (e), respectively, except for the positive inphase cases of the AO and WP. Areas with black dots denote $95 \%$ confidence level according to the two-tailed student's $t$ test 
latitude into the Korean Peninsula and Japan. This pattern is similar to the dipole-type blocking pattern at $100-140^{\circ} \mathrm{E}$, amongst the EAWM-related blocking patterns shown in Lee and Jhun (2006). On the contrary, when the AO and WP are positively in-phase, anomalous cyclonic circulation around eastern Siberia and anomalous anticyclone circulation from eastern China to the central North Pacific weaken the flow of cold air in the middle troposphere at high latitudes towards East Asia.

When the AO is positive, the polar vortex is strengthened, thereby strengthening the flow of zonal wind in the upper troposphere, and when the AO is negative, the polar vortex is weakened, causing the wind to meander in the upper troposphere. When the AO and WP are in-phase, such characteristics in the North Pacific become stronger (Fig. 5e, f). When the AO and WP are negatively in-phase, the EAJS migrates more to the south, and when positively in-phase, the EAJS migrates more to the north.

Figure 6 shows the composites of winter monthly atmospheric circulation anomaly when the AO and WP are outof-phase. The anomaly of atmospheric circulation around the North Atlantic region is similar to that when the AO and WP are in-phase, which indicates that the atmospheric circulation of the North Atlantic is related to the variation of the AO, but is independent from the variation of the WP. Unlike when the AO and WP are in-phase, the atmospheric circulation anomalies around the North Pacific show a great difference. When a negative $\mathrm{AO}$ is accompanied by a positive WP, the anomalous cyclonic circulation at the surface occurs in the Bering Sea and the Aleutian islands, which are located $45^{\circ}$ north of the North Pacific, and an anomalous anticyclonic circulation appears in the South China Sea of the North Pacific (Fig. 6a). This is because the Aleutian Low strengthens in the northeast and cannot expand to the southwest. The zonal pressure gradient at the surface only strengthens at the high latitudes of northeastern Asia. Therefore, the simultaneous occurrence of negative $\mathrm{AO}$ and positive WP does not have an obvious effect on the atmospheric circulation of East Asia. When a positive $\mathrm{AO}$ is accompanied by a negative WP, the pattern has a sign opposite to that of the pattern for simultaneous negative $\mathrm{AO}$ and positive WP, which is also not statistically significant (Fig. 6b). In case of a negative (positive) AO accompanied by positive (negative) WP (Fig. 6c, d), anomalous circulation in $500 \mathrm{hPa}$ level is similar to that at the surface (Fig. 6a, b). Anomalous cyclonic (anticyclonic) circulation occurs from Lake Baikal to southeast of the Aleutian Islands, and anomalous anticyclonic (cyclonic) circulation appears in the mid-latitudes of the Eurasian continent and western Pacific, resulting in an eastward (westward) expansion and westward (eastward) contraction of the EAT at high latitudes. The significant signal in $45^{\circ} \mathrm{N}$ south of East Asia is weaker or shifted southward compare to in-phase of the AO and WP. Therefore, over the East Asia area, the anomaly of HGT500 weakened the significance when the $\mathrm{AO}$ and WP are out-of-phase.

Thus far, the spatial structure of atmospheric circulation for each different combination of winter $\mathrm{AO}$ and WP phases has been examined. When the AO has the same sign as the WP, it strongly affects the winter temperatures of East Asia. Conversely, when the AO and WP have opposite signs to each other, the characteristics of the atmospheric circulation anomaly related to each index cancel each other out in the surrounding areas of East Asia, resulting in a statistically insignificant effect on the winter temperature over the region.

\subsection{Possible explanation of the combined effect of the AO and WP on EAWM circulation}

The biggest differences of SLP related to the EAWM between in-phase and out-of-phase for the AO and WP are eastward expansion of the Siberian High into Mongolia and Manchuria and an intensity of zonal gradient between the Siberian High and the Aleutian Low (Figs. 5a, 6a, and Figs. 5b, 6b). Chen et al. (2005) showed that the zonal wavenumber-2 (ZWN2) pattern of planetary waves contributes dominantly to anomalous SLP pattern related to the EAWM. Accordingly we investigated the ZWM2 patterns of SLP for individual cases of in-phase and outof-phase of the AO and WP using zonal Fourier harmonics (Fig. 7). Climatologically, the ZWN2 pattern has high pressures over the Eurasian and the North America continents and low pressures over the North Pacific and North Atlantic. This wave pattern corresponds to the climatological surface pressure systems, including the Siberian High, the Aleutian Low, the Canadian High and the Icelandic Low (Chen et al. 2005). Both the individual ZWN2 patterns of a negative (positive) AO and a negative (positive) WP show strong (weak) high pressures and low pressures over the continents and the oceans, respectively (Fig. 7a, b). The difference between the AO and WP is that the ZWN2 pattern related to the $\mathrm{AO}$ is significant in the whole of the climatological pattern, whereas the ZWN2 pattern related to the WP is significant in the southward of the climatological pattern. When the AO and WP are negatively (positively) in-phase, the climatological surface pressure system becomes stronger (weaker) and thus the Siberian High and the Aleutian Low in the same latitude with East Asia strengthen (weaken) and the zonal gradient between left and right regions of East Asia strengthens. On the contrary, when the AO and WP are out-of-phase, significant anomalous signals appear in the center (near $50^{\circ} \mathrm{N}$ ) of the climatological pattern due to the opposite sign between the ZWN2 patterns of the AO and WP; hence, there are no significant extensions of the Siberian High and the Aleutian Low into 
(a) SLP (N-AO/P-WP)

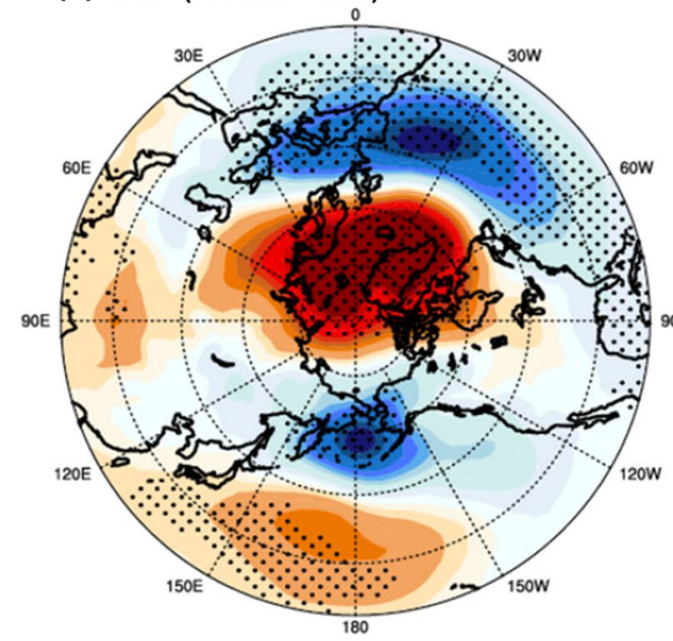

(c) HGT500 (N-AO/P-WP)

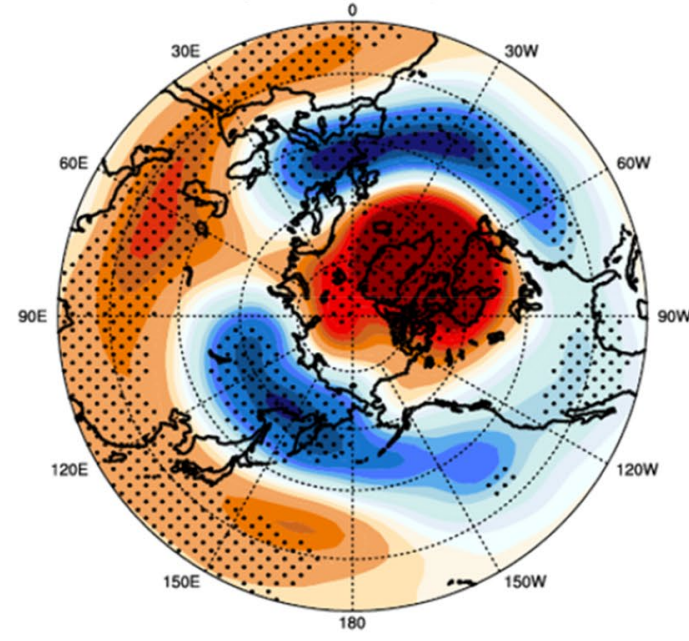

(e) U300 (N-AO/P-WP)

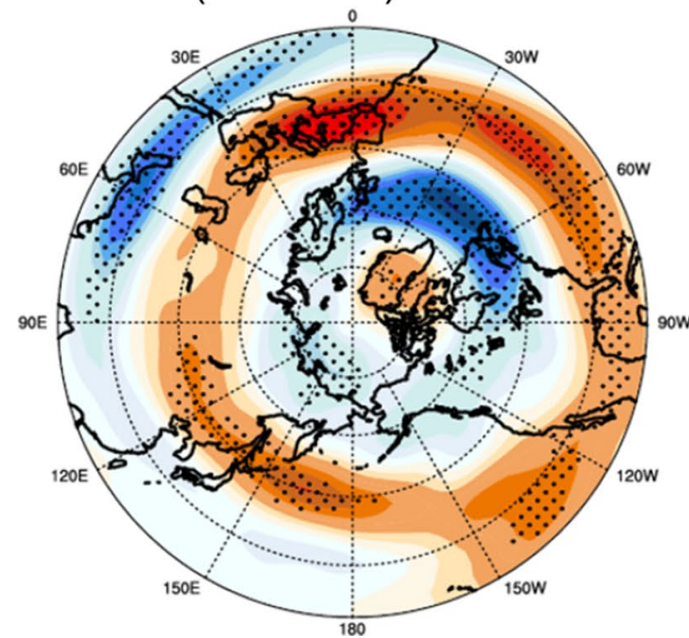

Fig. 6 Composite maps of a sea level pressure anomalies, b geopotential height anomalies at $500 \mathrm{hPa}$ and $\mathbf{c}$ zonal wind anomalies at $300 \mathrm{hPa}$ for the cases of negative AO and positive WP. The (b), (d) (b $\operatorname{SLP}(\mathrm{P}-\mathrm{AO} / \mathrm{N}-\mathrm{WP})$

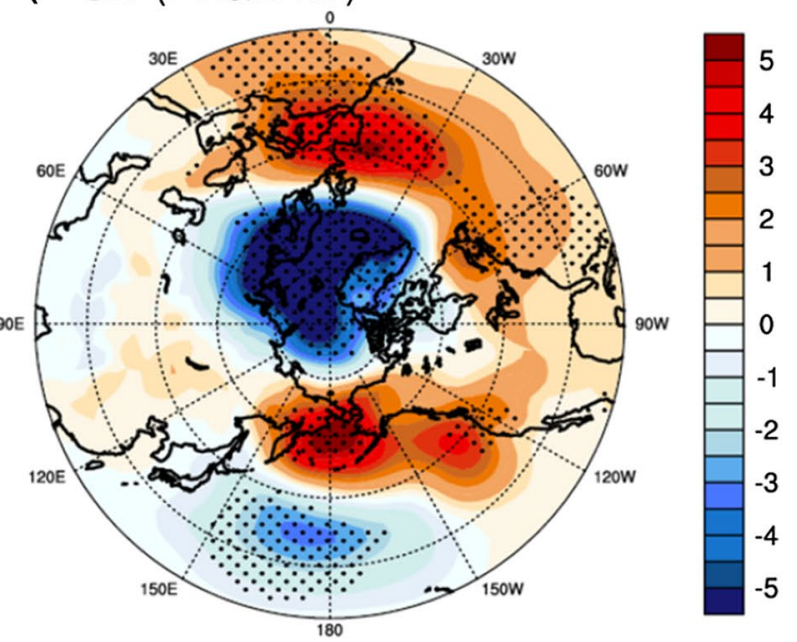

(d) HGT500 (P-AO/N-WP)

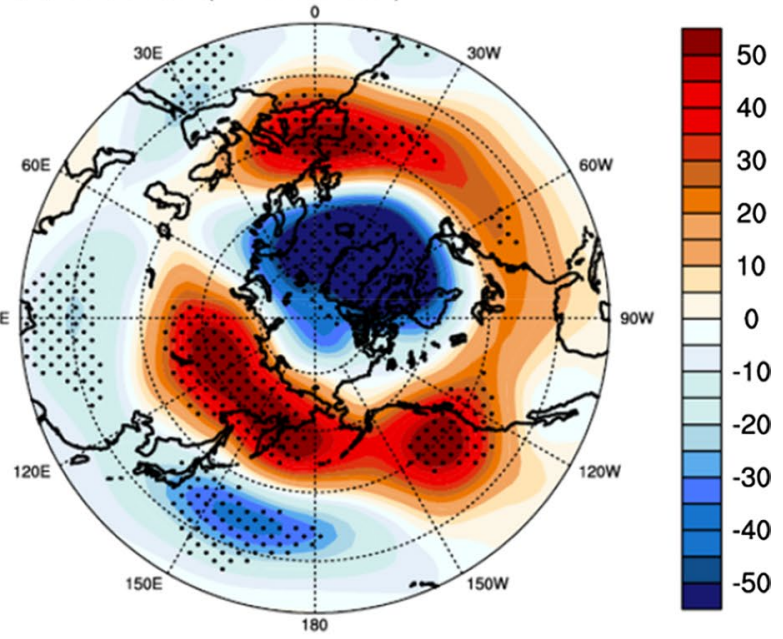

(f) $U 300(\mathrm{P}-\mathrm{AO} / \mathrm{N}-\mathrm{WP})$

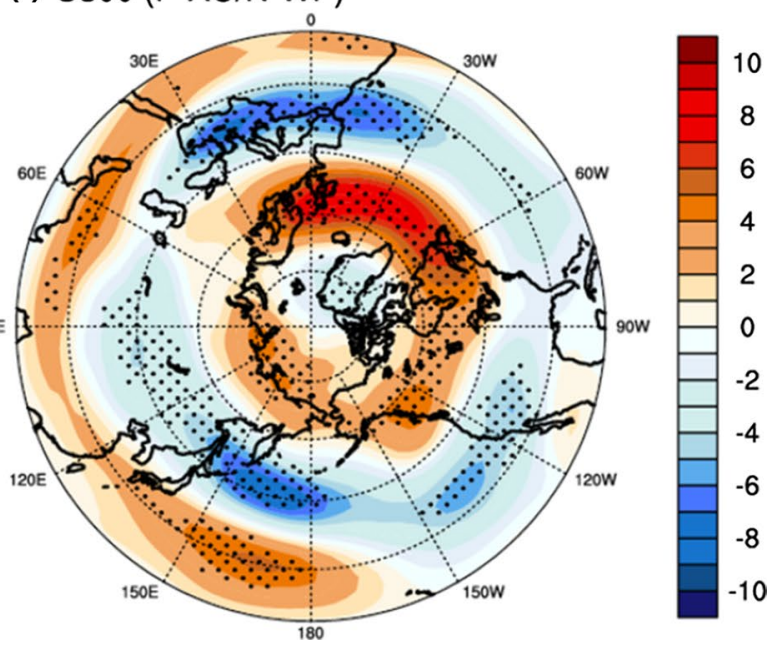

and (f) are the same as (a), (c) and (e), respectively, except for the cases of positive AO and negative WP. Areas with black dots denote $95 \%$ confidence level according to the two-tailed student's $t$ test 

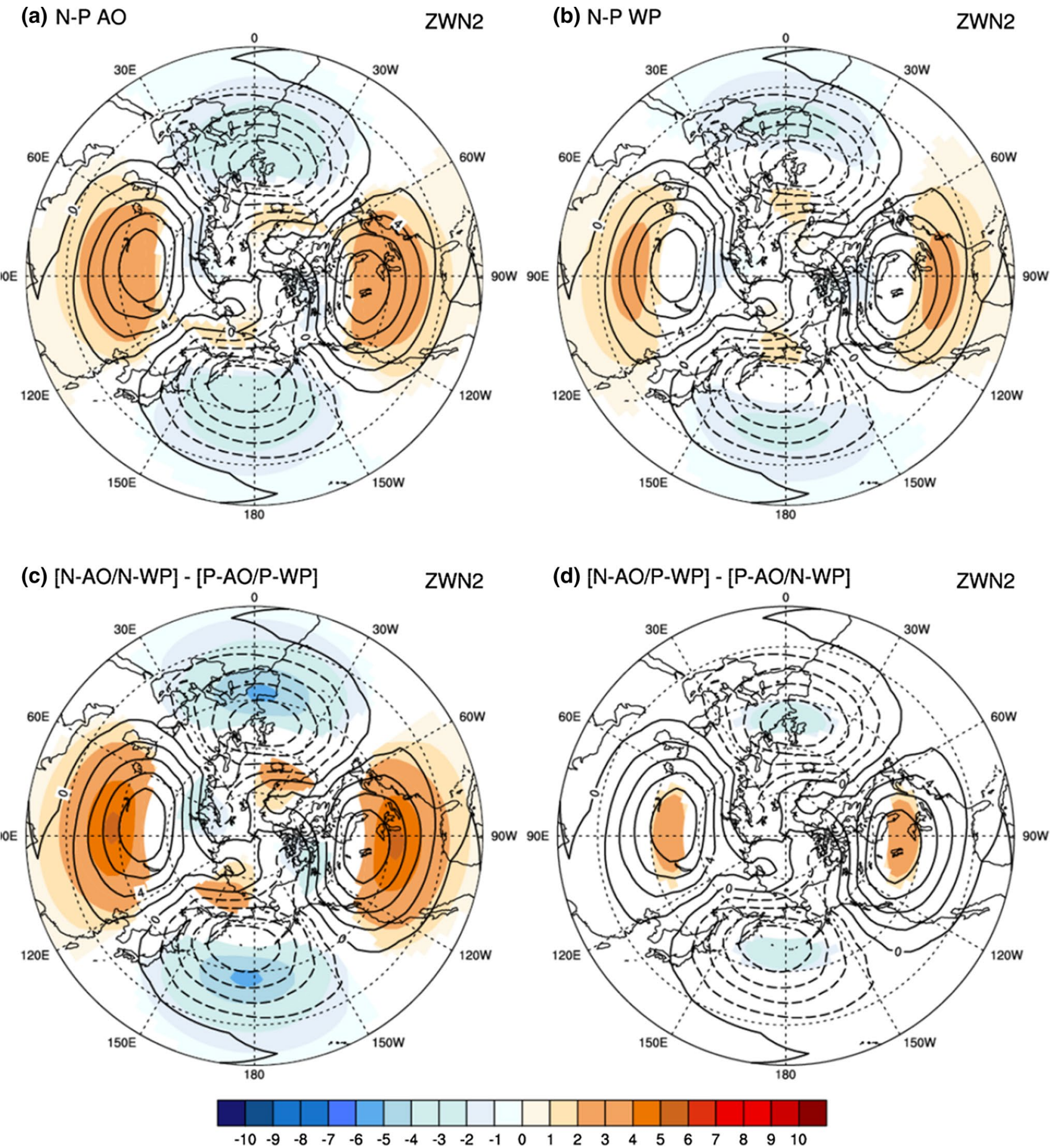

Fig. 7 Difference composite patterns (shading) of the zonal wave number-2 distribution of sea level pressure between the negative and positive a AO and $\mathbf{b}$ WP. $\mathbf{c}$ and $\mathbf{d}$ are the same but for in-phase and out-of-phase of AO and WP. Contour lines indicate the climatology of the zonal wave number and shadings denote significant values at $95 \%$ confidence levels
East Asia. These may explain the influence of the AO on EAWM circulation depending on the sign of the WP.

Additionally, the difference composite patterns of ZWN2 of HGT500 of the in- and out-of phases of the $\mathrm{AO}$ and WP are examined (Fig. 8). The individual ZWN2 patterns of HGT500 for the AO and WP are similar to each other (not shown) as that of SLP. Therefore, when the AO and WP are negatively (positively) in-phase, a climatological negative eddy over East Asia is shifted southward and thus the EAT becomes deeper (shallower) over East Asia 


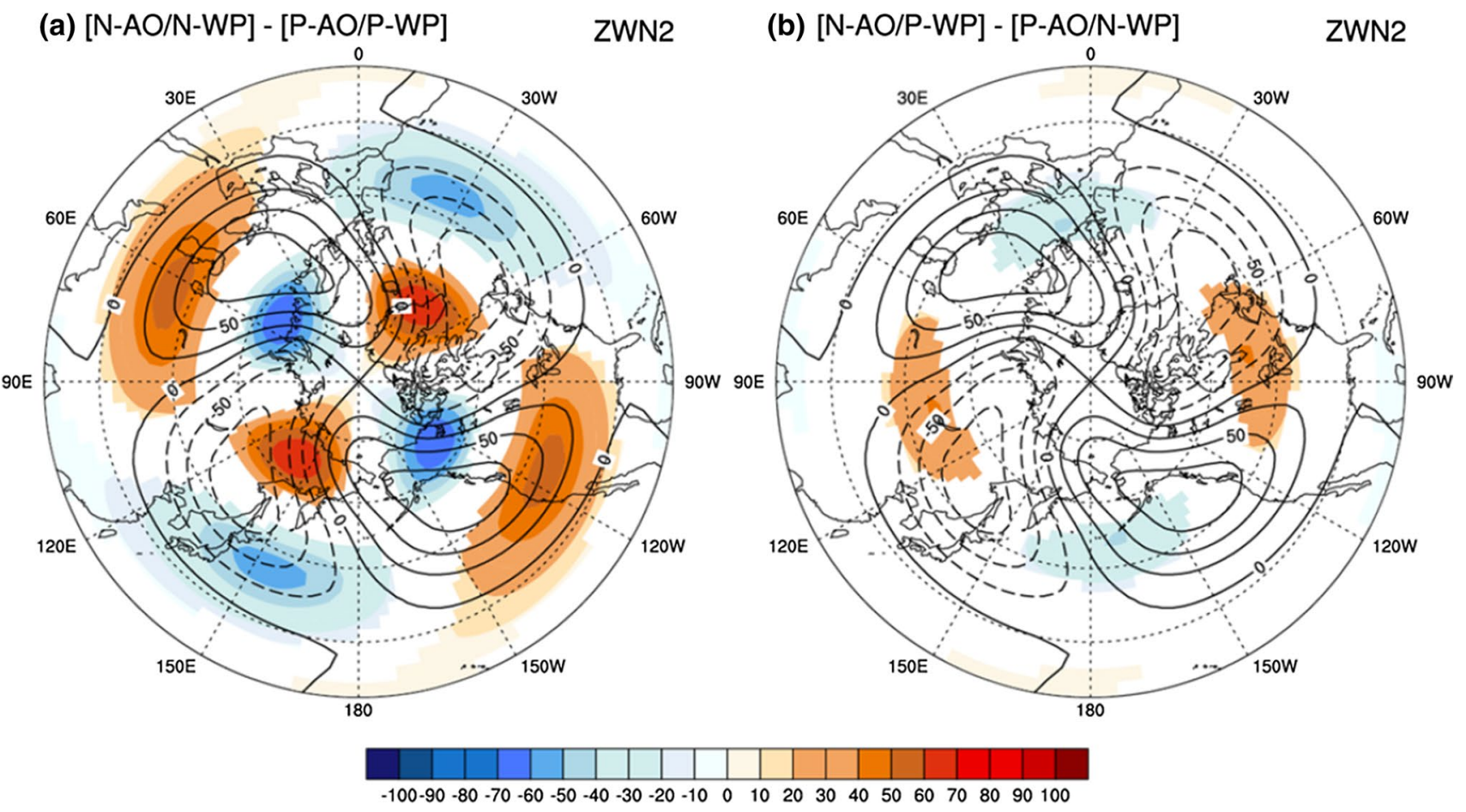

Fig. 8 As in Fig. 7c, d, but for geopotential height at $500 \mathrm{hPa}$

(Figs. 8a and 5c, d). On the other hand, when the $\mathrm{AO}$ and WP are out-of-phase, there are no significant anomalous eddies related to EAT (Fig. 8b).

\subsection{A new EAWM index based on the combination of $\mathrm{AO}$ and WP phases}

In this section, an index, which considers both the effects of the AO and WP on T2m_EA, is suggested based on the result that statistically significant negative (positive) temperature anomalies in East Asia are more evident when the $\mathrm{AO}$ and WP are positively (negatively) in-phase than when they are out-of-phase (Fig. 9).

In contrast to the existing EAWM indices (e.g., Jhun and Lee 2004; Sun and Li 1997; Wang et al. 2009; Li and Yang 2010) that use the synoptic variables related to the EAWM, this index utilizes the large-scale teleconnection pattern indices, the $\mathrm{AO}$ and WP indices, related to the EAWM. A multiple linear regression is carried out using the AO and WP indices as predictors, and T2m_EA as the predictand. To find each regression coefficient of the predictors, leave-one-out cross-validation (Michaelsen 1987) is utilized to find 56 regression coefficients each, for the AO and WP indices, which are then averaged. Finally, the average regression coefficients of the AO and WP indices are multiplied to create the EA_T2m variation. This newly developed index of the AO and WP is referred as the AOWP index in this study. Figure 10 shows the correlation coefficients between the monthly and seasonal T2m_EA and AO, PNA, WP, and AOWP indices. All correlations between the AOWP and T2m_EA of each month are statistically significant with the $99 \%$ confidence level and the coefficient of January (0.66) is higher than those for December (0.4) and February (0.53). Furthermore, the correlation between T2m_EA and the AOWP indices for all winter months is 0.52 , which is statistically significant at the $99 \%$ confidence level, and the correlation coefficient between the seasonal mean indices is the highest $(0.70)$. When both two indices are taken into consideration, the relationship with East Asia winter temperature becomes higher than when just one index (AO or WP) is considered.

Figure 11 is the regression map of the winter East Asia atmospheric circulation for the winter AOWP index, which is similar to the positive in-phase pattern in Fig. 5. For positive AOWP, the T2m anomalies are higher than in normal months from central Siberian to the Korea Peninsula and Japan and lower than that of normal months in eastern Siberia. In the lower and middle levels of the troposphere, the anomalous anticyclonic circulation is zonally stretched out over the mid-latitude of North Pacific and the anomalous cyclonic circulation is located in North Pole. In particular, in the $500 \mathrm{hPa}$ level, the anomalous cyclonic circulation is centered in the eastern Siberia, where the negative T2m anomalies are located. Due to the strengthening of the pressure gradient in the meridional direction, the zonal wind in $300 \mathrm{hPa}$ level around $50^{\circ} \mathrm{N}$ is stronger than during normal 


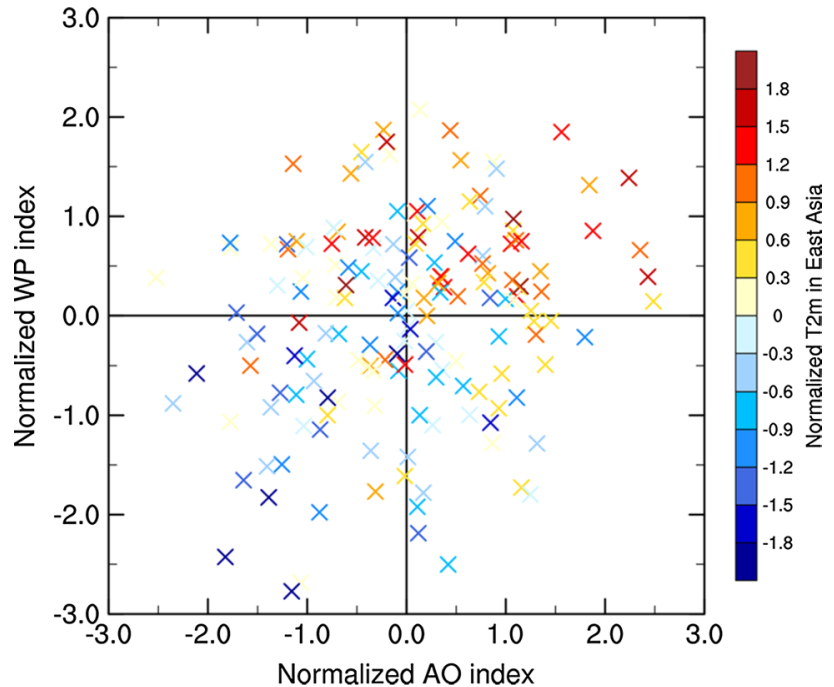

Fig. 9 Scatter plot of normalized temperature anomalies at $2 \mathrm{~m}$ in East Asia region (T2m_EA) according to the phases of normalized $\mathrm{AO}$ and WP indices. The color of the ' $X$ ' makers denotes the degrees of normalized $\mathrm{T} 2 \mathrm{mEA}$

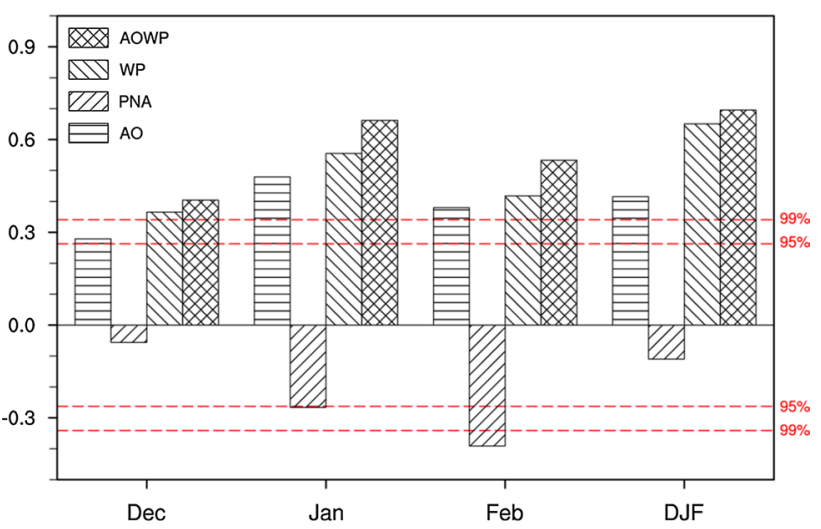

Fig. 10 Correlation coefficients between monthly and seasonal temperature anomalies at $2 \mathrm{~m}$ averaged in the East Asia region $\left(25^{\circ}\right.$ $\left.45^{\circ} \mathrm{N}, 110^{\circ}-145^{\circ} \mathrm{E}\right)$ and $\mathrm{AO}, \mathrm{PNA}, \mathrm{WP}$, and AOWP indices during winter (December, January and February) of 1958/1959-2013/2014. The dashed lines denote the 95 and $99 \%$ confidence levels

months and a negative zonal wind anomaly is located in south $50^{\circ} \mathrm{N}$, resulting in the northward shift of EAJS.

The correlation coefficients between the six different EAWM indices and the AOWP index are shown in Table 3. The Siberian High (SH) (Wu and Wang 2002), Aleutian Low (AL) (Trenberth and Hurrell 1994), zonal pressure gradient between SH and AL (SH-AL), EAT (Sun et al.), trough axis index (TAI) (Wang et al. 2009), and EAJS (Jhun and Lee 2004) indices are known to represent EAWM. Most indices, except for the TAI, have a statistically significant correlation with AOWP, and SH and AL have statistically significant relationships depending on the month.
The EAT showed the greatest correlation coefficients with the AOWP for all months. This signifies that the AO and WP affect the temperature in East Asia by transforming the strength and shape of the EAT, which changes the direction of the flow of cold air in the high latitude flow to East Asia.

\section{Summary and conclusions}

This study investigates the combined effect of the AO and WP on the northern hemisphere and East Asia winter temperature variations through a composite analysis by utilizing NCEP/NCAR Reanalysis data from the last 56 years (1958/1959-2013/2014). Before analyzing the combined effect of the AO and WP on the boreal winters, the independent effects of the AO and WP were investigated. The temperature variation around the North Atlantic regions is not strongly affected by the WP phase difference, but does show statistically significant changes depending on the AO phase. Meanwhile, the AO and WP independently affect winter temperature variations in East Asia. The AO mostly affects the temperature anomaly in northern Eurasia to northern East Asia, whereas the WP affects the temperature anomaly in eastern Siberia and Southeast Asia.

When the AO and WP are in-phase, the negative relationship between the temperature of East Asia and the AO is strengthened. In other words, during the winter months, when negative (positive) AO is accompanied by negative (positive) WP, negative (positive) temperature anomalies are primarily dominant in East Asian regions (Northeastern China, the Korean Peninsula, and Japan). Conversely, when the AO and WP are out-of-phase (negative AO phase with positive WP phase, and positive AO phase with negative WP phase), the temperature anomalies of East Asian winter do not show distinct changes.

The anomalous circulation in the North Pacific, which appears when the AO and WP are in the same phase, strengthens and expands to the southwest. Hence, when a negative (positive) AO appears with a negative (positive) WP, the anomalous cyclonic (anticyclonic) circulation in the North Pacific expands to the southwest. Therefore, on the surface, the zonal pressure gradient centered around East Asia is strengthened (weakened), thereby strengthening the northwesterly wind to East Asia. Furthermore, the EAT is strengthened (weakened) in the middle troposphere, making it possible for more (less) cold air from high latitudes to flow into East Asia. Through correlation analysis, the combined $\mathrm{AO}$ and WP affect the characteristics of atmospheric circulation related with the EAWM and show the highest correlation with the variation of EAT. On the other hand, when the AO and WP are out-of-phase with each other, the atmospheric circulation patterns of the North Pacific and East Asia cancel each other out, do not 
(a) T2M

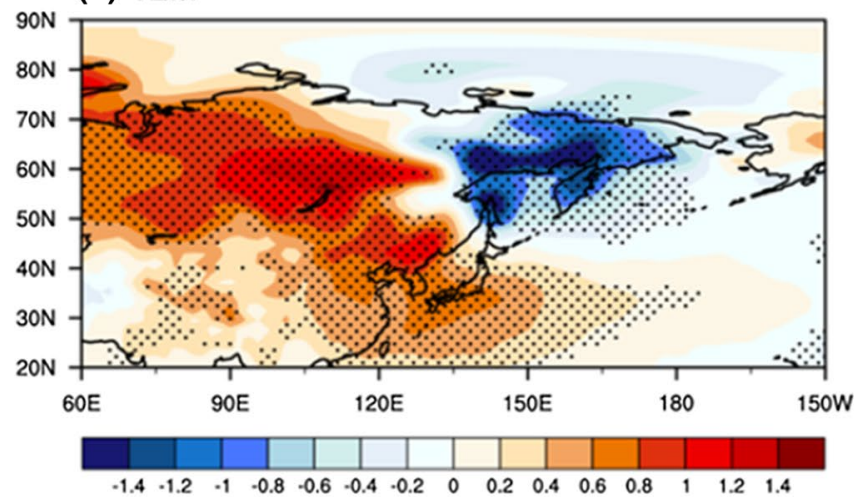

(c) HGT500

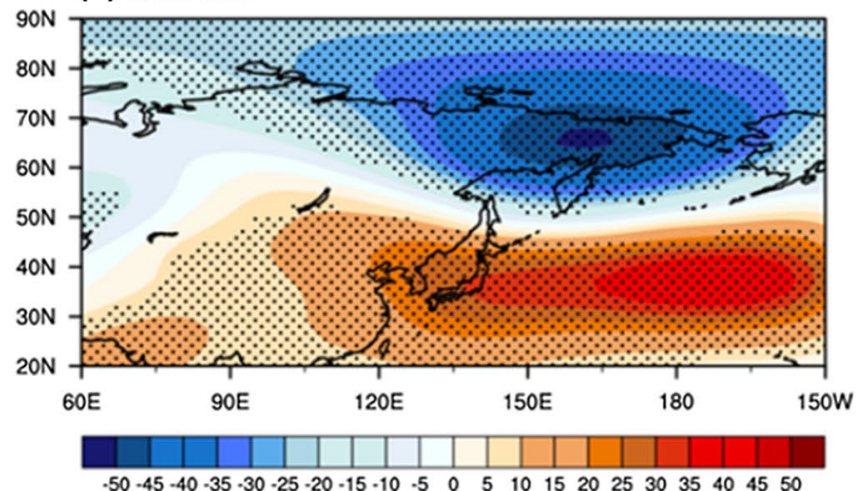

Fig. 11 Regression maps of a temperature anomalies at $2 \mathrm{~m}$, b sea level pressure anomalies, c geopotential height anomalies at $500 \mathrm{hPa}$ and $\mathbf{d}$ zonal wind anomalies at $300 \mathrm{hPa}$ with regard to the combined index of the AO and WP (AOWP) during winter (December, Janu-

show a significant pattern, and thus do not have a distinct effect on the winter temperature variation in East Asia.

The zonal wavenumber-2 patterns of SLP and HGT500 for in-phase and out-of-phase of the AO and WP are also investigated to explain the influence of the AO on EAWM circulation depending on the sign of the WP. Both of the individual anomalous $\mathrm{ZWN} 2$ patterns of a negative $\mathrm{AO}$ and a negative WP are positive over Eurasia and North America

Table 3 Temporal correlation coefficients between the AOWP index and six different circulation indices related with the EAWM during the boreal winter 1958/1959-2013/2014

\begin{tabular}{lcccc}
\hline & DEC & JAN & FEB & DJF monthly \\
\hline SH & $-0.28^{*}$ & $-0.29 *$ & -0.2 & -0.26 \\
AL & $0.28^{*}$ & 0.15 & $0.36 * *$ & 0.26 \\
SH-AL & $-0.35^{* *}$ & $-0.27 *$ & $-0.37 * *$ & $-0.33^{* *}$ \\
EAT & $0.59^{* *}$ & $0.75^{* *}$ & $0.62^{* *}$ & $0.65 * *$ \\
TAI & 0.11 & -0.04 & -0.02 & 0.02 \\
EAJS & $-0.49^{* *}$ & $-0.39 * *$ & $-0.29 *$ & $-0.39 * *$ \\
\hline
\end{tabular}

The values with one and two asterisks exceed the 95 and $99 \%$ confidence levels according to the two-tailed student's $t$ test, respectively (b) SLP

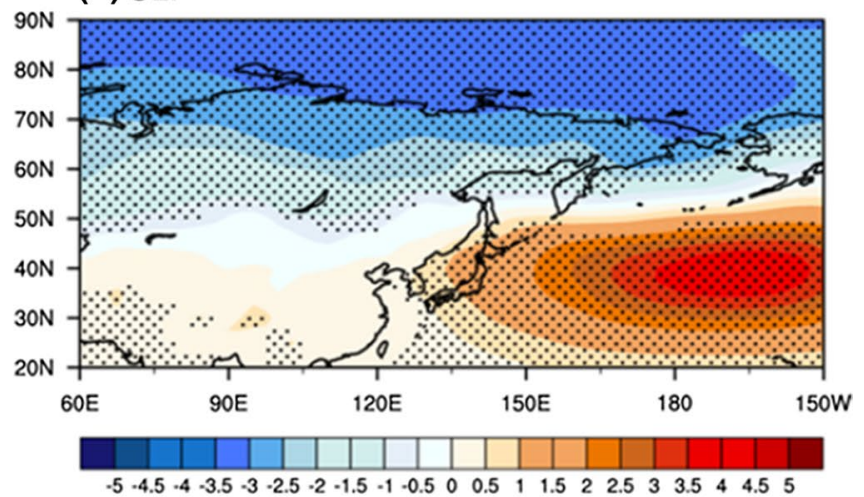

(d) U 300

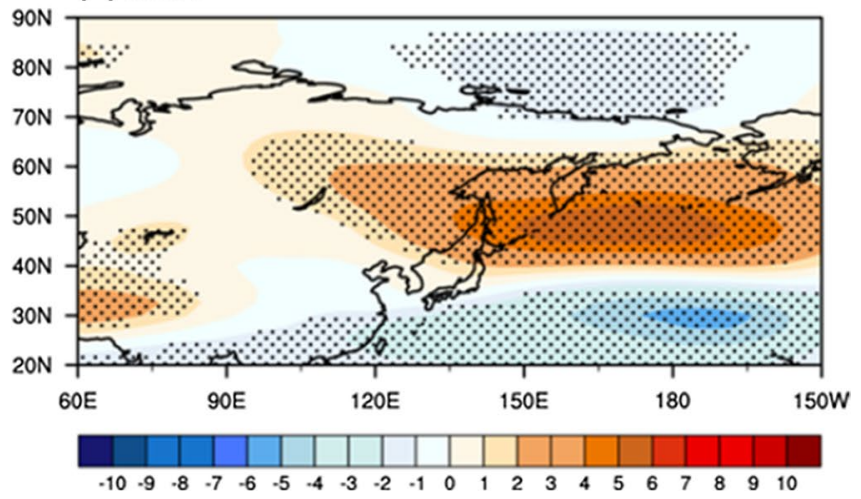

ary and February) of 1958/1959-2013/2014. Areas with black dots denote $95 \%$ confidence level according to the two-tailed student's $t$ test

and negative over North Pacific and North Atlantic, especially in middle latitude. Therefore, this signal strengthens the climatological pattern, and when the AO and WP are in-phase, the south part of Siberian High and Aleutian Low become stronger than the normal condition. Hence, the zonal pressure gradient in the middle latitude centered in the Korean Peninsula and Japan becomes stronger. Consequently, continental cold air of high latitude flows more southeastward into East Asia by the strong northwesterly wind. On the contrary, when the AO and WP are out-ofphase, anomalous ZWN2 signals cancel each other out in the middle latitude, which prevents any significant extensions of the Siberian High and the Aleutian Low into East Asia. The anomalous ZWN2 patterns of HGT500 are similar to those of SLP. There are significant variations of the ZWN2 pattern related to EAT over the Korean Peninsula and Japan during the in-phase of the AO and WP. However, the anomalous ZWN2 pattern for their out-of-phase is not significant over the region.

Based on the fact that the effect of the $\mathrm{AO}$ on winter temperature in East Asia can be changed depending on the phase of the WP pattern in the North Pacific, the AOWP index is 
suggested in this study. The index is significantly correlated with the EAT and EAJS, and surface air temperature.

Linkin and Nigam (2008) showed that the WP pattern in the middle troposphere is similar to the North Pacific Oscillation (NPO) pattern in SLP. Yeh et al. (2011) revealed that a climate shift in the North Pacific occurred in winter 1966/1977 and 1988/1989, and showed through empirical orthogonal function analysis that the leading atmospheric circulation of the lower troposphere transformed from the pattern related to the intensity of the Aleutian Low to the NPO pattern. In this study, because the anomalous temperature pattern in East Asia related to the WP is analyzed by case selection, the present study results are not affected by the change of the leading mode of atmospheric circulation in the North Pacific. However, considering the recent increase of the NPO pattern in the mid-latitudes of the North Pacific (Yeh et al. 2011), it can be inferred that the effect of the AO on East Asia winter temperature after winter 1988/1989 can be further modified by the above and below normal condition of the WP, compared to before winter 1988/1989. In fact, a comparison of the number of occurrences of the WP before and after 1988/1989 shows that before 1988/1989, among a total of 90 months (30 years $\times 3$ months), negative and positive WPs occurred in 20 and 19 months, respectively, and after 1988/1989, among a total of 78 months ( 26 years $\times 3$ months), negative and positive WPs occurred in 16 and 19 months, respectively (Table 2). The differences between the negative WPs before and after the climate regime shift are not distinct, but positive WPs occur more frequently after 1988/1989 than before. The negative in-phase occurrence of AO and WP before and after 1988/89 does not increase, but the number of positive in-phase occurrences increases (before 1988/1989: 8 cases; after 1988/1989: 14 cases). This distinct increase only in the positive in-phase cases of the AO and WP after the climate regime shift could be related to the decadal change of the WP and AO phases. Thus additional studies on this regard need to be conducted.

Acknowledgments This work was funded by the Korea Meteorological Administration Research and Development Program under grant KMIPA 2015-2081.

Open Access This article is distributed under the terms of the Creative Commons Attribution 4.0 International License (http://creativecommons.org/licenses/by/4.0/), which permits unrestricted use, distribution, and reproduction in any medium, provided you give appropriate credit to the original author(s) and the source, provide a link to the Creative Commons license, and indicate if changes were made.

\section{References}

Barnston AG, Livezey RE (1987) Classification, seasonality and persistence of low-frequency atmospheric circulation patterns. Mon Weather Rev 115:1083-1126

Chen Y, Zhai P (2011) Interannual to decadal variability of the winter aleutian low intensity during 1900-2004. J Meteorol Res 25(6):710-724
Chen W, Yang S, Huang R-H (2005) Relationship between stationary planetary wave activity and the East Asian winter monsoon. J Geophys Res 110:D14110. doi:10.1029/2004/JD005669

Chen W, Lan XQ, Wang L, Ma Y (2013) The combined effects of the ENSO and the Arctic Oscillation on the winter climate anomalies in East Asia. Chin Sci Bull 58:1355-1362. doi:10.1007/ s11434-012-5654-5

Cohen J, Foster J, Marlow M, Saito K, Jones J (2010) Winter 2009_ 2010: a case study of an extreme Arctic Oscillation event. Geophys Res Lett 37:L17707. doi:10.1029/2010GL044256

Deser C (2000) On the teleconnectivity of the "Arctic Oscillation". Geophys Res Lett 27:779-782

Di Lorenzo E, Cobb KM, Furtado JC, Schneider N, Anderson BT, Braccor A, Alexander MA, Vimont DJ (2010) Central Pacific El Nino and decadal climate change in the North Pacific Ocean. Nat Geosci 3:762-765

Gong D-Y, Wang S-W, Zhu J-H (2001) East Asian winter monsoon and Arctic Oscillation. Geophys Res Lett 28:2073-2076

Greatbatch RJ (2000) The North Atlantic Oscillation. Stoch Environ Risk Assess 14:213-242

He SP, Wang HJ (2013a) Impact of the November/December Arctic Oscillation on the following January temperature in East Asia. J Geophys Res 118:12981-12998. doi:10.1002/2013JD020525

He SP, Wang HJ (2013b) Oscillating relationship between the East Asian winter monsoon and ENSO. J Clim 26:9819-9838

Holton JR, Curry JA (2002) Encyclopedia of atmospheric sciences, 1 st edn. Academic Press, Elsevier Science, London

Jeong J-H, Ho C-H (2005) Changes in occurrence of cold surges over East Asia in association with Arctic Oscillation. Geophys Res Lett 32:L14704. doi:10.1029/2005GL023024

Jhun J-G, Lee E-J (2004) A new East Asian winter monsoon index and associated characteristics of winter monsoon. J Clim 17:711-726

Kalnay E, Kanamitsu M, Kistler R, Collins W, Deaven D, Gandin L, Iredell M, Saha S, White G, Woollen J (1996) the NCEP/NCAR 40-year reanalysis project. Bull Am Meteorol Soc 77(3):437-471

Kim H-J, Ahn J-B (2012) Possible impact of the autumnal North Pacific SST and November AO on the East Asian winter temperature. J Geophys Res 117:D12104. doi:10.1020/2012JD017527

Kim J-W, Yeh S-W, Chang E-C (2014) Combined effect of El NinoSouthern Oscillation and Pacific Decadal Oscillation on the East Asian winter monsoon. Clim Dyn 42:957-971

Konrad CE (1998) Intramonthly indices of the Pacific/North American teleconnection pattern and temperature regimes over the United States. Theor Appl Climatol 60:11-19

Lee H-S, Jhun J-G (2006) Two types of the Asian continental blocking and their relation to the east Asian monsoon during the boreal winter. Geophys Res Lett 33:L22707. doi:10.1029/2006/ GL027948

Li Y, Yang S (2010) A dynamical index for the East Asian winter monsoon. J. Climate 23:4255-4262

Li F, Wang HJ, Gao YQ (2014) On the strengthened relationship between East Asian Winter Monsoon and Arctic Oscillation: a comparison of 1950-1970 and 1983-2012. J Clim 27(13):50755091. doi:10.1175/JCLI-13-00335.1

Linkin Megan E, Nigam S (2008) The North Pacific Oscillation-West Pacific Teleconnection pattern: mature-phase structure and winter impacts. J Clim 21:1979-1997

Michaelsen J (1987) Cross-validation in statistical climate forecast models. J Clim Appl Meteorol 26:1589-1600

Minobe S, Mantua N (1999) Interdecadal modulation of interannual atmospheric and oceanic variability over the North Pacific. Prog Oceanogr 43:163-192

Park T-W, Ho C-H, Yang S (2011) Relationship between the Arctic Oscillation and Cold Surges over East Asia. J Clim 24:68-83

Rasmusson EM, Wallace JM (1983) Meteorological aspects of the El Nino/Southern Oscillation. Science 222:1195-1202 
Sakai K, Kawamura R (2009) Remote response of the East Asian winter monsoon to tropical forcing related to El Nino-Southern Oscillation. J Geophys Res 114:D06105. doi:10.1029/200 8JD010824

Sun BM, Li CY (1997) Relationship between the disturbances of East Asian trough and tropical convective activities in boreal winter. Chin Sci Bull 42:500-504

Sun J, Wang HJ (2006) Relationship between Arctic Oscillation and Pacific Decadal Oscillation on decadal timescale. Chin Sci Bull 51:75-79

Thompson DWJ, Wallace JM (1998) The Arctic oscillation signature in wintertime geopotential height and temperature fields. Geophys Res Lett 25:1297-1300. doi:10.1029/98GL00950

Thompson DWJ, Wallace JM (2000) Annular modes in the extratropical circulation Part I: month-to-month variability. J Clim 13:1000-1016

Thompson DWJ, Wallace JM (2001) Regional climate impacts of the northern hemisphere annular mode. Science 293:85-89

Trenberth KE, Hurrell JW (1994) Decadal atmosphere-ocean variations in the Pacific. Clim Dyn 9:303-319

Wallace JM, Gutzler DS (1981) Teleconnections in the geopotential height field during the northern hemisphere winter. Mon Weather Rev 109:784-812

Wang L, Chen W (2010) Downward Arctic Oscillation signal associated with moderate weak stratospheric polar vortex and the cold December 2009. Geophys Res Lett 37:L09707. doi:10.1029/201 0GL042659

Wang L, Chen W (2014) An Intensity Index for the East Asia winter monsoon. J Clim 27:2361-2374
Wang L, Chen W, Huang R (2008) Interdecadal modulation of PDO on the impact of ENSO on the East Asian winter monsoon. Geophys Res Lett 35:L20702. doi:10.1029/2008GL035287

Wang L, Chen W, Zhou W, Huang R (2009) Interannual variations of East Asian trough axis at $500 \mathrm{hPa}$ and its association with the East Asian winter monsoon pathway. J Clim 22:600-614

Wang B, Wu R, Fu X (2000) Pacific-East Asian teleconnection: How does ENSO affect East Asian climate? J Clim 13:1517-1536

Wang B, Wu Z, Chang C-P, Liu J (2010) Another look at interannualto-interdecadal variations of the East Asian winter monsoon: the northern and southern temperature modes. J Clim 23:1495-1512

Wu B, Wang J (2002) Winter Arctic Oscillation, Siberian high and East Asian winter monsoon. Geophys Res Lett 19:1897-1990

Wu B, Zhang R, D'Arrigo R (2006) Distinct modes of the East Asian winter monsoon Mon. Weather Rev 134:2165-2179

Xiao F, Jiang H, Wu B, Wang H, Li X (2014) The leading correlation of the winter Aleutian low with surface air temperature during the subsequent summer over the Arctic and its possible mechanism. Chin Sci Bull 59:904-912

Yeh S-W, Kang Y-J, Noh Y, Miller AJ (2011) The North Pacific climate transitions of the winters of 1976/77 and 1988/89. J Clim 24:1170-1183

Zhang R, Sumi A, Komoto M (1996) Impact of El Nino on the East Asian monsoon: a diagnostic study of the' $86 / 87$ and' $91 / 92$ events. J Meteorol Soc Jpn 74(1):49-62 